\title{
Atividades biológicas de plantas medicinais utilizadas na Medicina Veterinária no Brasil entre 2000 e 2020: Uma revisão de literatura
}

\author{
Biological activities of medicinal plants used in Veterinary Medicine in Brazil between 2000 and
} 2020: A literature review

Actividades biológicas de plantas medicinales utilizadas en Medicina Veterinaria en Brasil entre 2000 y 2020: Una revisión de la literatura

\begin{abstract}
Resumo
O tratamento de enfermidades à base de plantas medicinais é uma prática antiga e que vem ganhando especial atenção na área da ciência médica, sobretudo, na medicina veterinária, onde vários estudos científicos já comprovaram a eficácia de inúmeras plantas como possível alternativa ao uso de fármacos convencionais. Nesta perspectiva, o objetivo dessa revisão de literatura foi reunir estudos científicos realizados no Brasil sobre a eficácia terapêutica de plantas medicinais com possível aplicação na medicina veterinária. Para tal, foram selecionados 114 artigos (pesquisados nas bases de dados Google Acadêmico, SciELO, PubMed, Science Direct e MEDLINE) para compor essa revisão. Foram comprovadas as atividades biológicas de mais de 70 plantas, concluindo-se que as plantas são alternativas eficientes e seguras para o tratamento de doenças na medicina veterinária.
\end{abstract}

Palavras-chave: Fitoterapia; Etnoveterinária; Brasil.

\begin{abstract}
The treatment of diseases based on medicinal plants is an old practice that has gaining special attention in the area of medical science, especially in veterinary medicine, where several scientific studies have already proven the effectiveness of countless plants as a possible alternative to the use of conventional drugs. In this perspective, the objective of this literature review was to gather scientific studies carried out in Brazil on the therapeutic efficacy of medicinal plants with possible application in veterinary medicine. To this end, 114 articles (searched in Google Academic, SciELO, PubMed, Science Direct and MEDLINE databases) were selected to compose this review. The biological activity of more than 70 plants has been proven, concluding that plants are efficient and safe alternatives for the treatment of diseases in veterinary medicine.
\end{abstract}

Keywords: Phytotherapy; Ethnoveterinary; Brazil. 


\begin{abstract}
Resumen
Actividades biológicas de plantas medicinales utilizadas en medicina veterinaria en Brasil entre 2000 y 2020: una revisión de la literatura. El tratamiento de enfermedades a base de plantas medicinales es una práctica milenaria que ha ido ganando especial atención en el área de la ciencia médica, especialmente en la medicina veterinaria, donde varios estudios científicos ya han demostrado la eficacia de numerosas plantas como posible alternativa al uso de medicamentos convencionales. En esta perspectiva, el objetivo de esta revisión de la literatura fue recopilar estudios científicos realizados en Brasil sobre la eficacia terapéutica de plantas medicinales con posible aplicación en medicina veterinaria. Para ello, se seleccionaron 114 artículos (buscados en las bases de datos Google Academic, SciELO, PubMed, Science Direct y MEDLINE) para componer esta revisión. Se comprobó la actividad biológica de más de 70 plantas, concluyendo que las plantas son alternativas eficientes y seguras para el tratamiento de enfermedades en medicina veterinaria.
\end{abstract}

Palabras clave: Fitoterapia; Etnoveterinária; Brasil.

\title{
1. Introdução
}

A etnoveterinária é a ciência que envolve o conhecimento e as práticas populares utilizadas para o tratamento ou prevenção das doenças que acometem os animais. Na terapêutica são empregados produtos de origem mineral, animal e, principalmente a utilização de plantas medicinais (Lans, 2019). É o conhecimento convencional e suas habilidades aliadas, usadas para o cuidado de saúde dos animais (Khattal et al., 2015). O tratamento de doenças nos animais normalmente se assemelha ao tratamento de doenças humanas, desta forma, as mesmas plantas medicinais podem ser usadas tanto para humanos quanto para os animais (Ahmad et al., 2017).

O uso de produtos naturais sempre fez parte dos costumes em todas as sociedades, seja para cura ou alívio de doenças que acometem os homens ou animais; são muitas as informações e experiências que vêm sendo acumuladas ao longo das gerações. Dessa forma, essa prática terapêutica e a diversidade estrutural dos produtos naturais tem sido muitas vezes o ponto de partida para as pesquisas científicas que na grande maioria provêm do conhecimento empírico (Hernandez-Rivera, 2017, Scapinello et al., 2019).

As plantas medicinais permanecem como as principais alternativas de tratamento em várias partes do mundo, considerando o uso de soluções à base de plantas para fins terapêuticos (Cragg \& Newman, 2013; Dar et al., 2017; Moroole et al., 2019). Nesse sentido, o uso de plantas medicinais no tratamento dos animais vem crescendo gradativamente, principalmente na área de produção, diante da exigência do consumidor em adquirir produtos cada vez mais saudáveis, produzidos dentro dos padrões da agroecologia, seguros e livres de resíduos (Brandão, 2006). Segundo tal interesse de se encontrar alternativas ao uso de fármacos convencionais na medicina veterinária, muitas plantas medicinais já tiveram suas atividades comprovadas cientificamente.

Diante disso, a presente pesquisa tem por finalidade a revisão bibliográfica de estudos científicos veterinários realizados nos últimos 20 anos sobre as atividades biológicas de plantas endêmicas e exóticas no país. Assim, será exibido de forma sucinta um panorama das atividades mais promissoras, incentivando e direcionando os estudos de novas alternativas terapêuticas na medicina veterinária.

\section{Metodologia}

O levantamento bibliográfico de estudos científicos das atividades biológicas de plantas medicinais na medicina veterinária no Brasil foi realizado utilizando as bases de dados, Google Acadêmico, SciELO, PubMed, Science Direct e MEDLINE. Para tal, diferentes combinações das palavras-chave "plantas medicinais", "etnoveterinária", "medicina veterinária" e seus correspondentes em português e inglês foram utilizadas. Não foi contatado nenhum investigador e foram analisados somente artigos publicados nos últimos vinte anos (2000 a 2020). A partir desse ponto foi realizada uma pré-seleção dos artigos de acordo com o título e resumo e, posteriormente, uma nova seleção para análise dos artigos na íntegra. Os seguintes critérios 
de inclusão foram aplicados: estudos científicos veterinários brasileiros sobre atividade biológica de plantas medicinais, em modelos in vitro e/ou in vivo. Os critérios para exclusão de artigos foram: duplicação, artigo de revisão, meta-análise, resumos, anais de congressos científicos, trabalhos acadêmicos, editoriais, cartas, relatos de caso e estudos voltados para humanos.

\section{Resultados}

Inicialmente, na pesquisa por palavra-chave, foram identificados 5.709 artigos, distribuídos nas bases de dados consultadas da seguinte forma: Google Acadêmico (5.410), SciELO (23), PubMed (66), Science Direct (201) e MEDLINE (9). Após análise dos títulos e resumos e atenção aos critérios de inclusão e exclusão, 182 artigos foram selecionados para leitura na íntegra: 97 do Google Acadêmico, 6 do SciELO, 15 do PubMed, 63 do Science Direct e 1 do MEDLINE. Desses artigos, foram excluídas 70 duplicatas, resultando em 112 artigos. Ainda foram incluídos 2 artigos localizados através da busca manual das referências dos artigos selecionados, totalizando 114 artigos finais. A figura 1 apresenta um fluxograma, o qual resume o processo de seleção dos artigos para compor a presente revisão.

Figura 1. Fluxograma para seleção dos estudos encontrados.

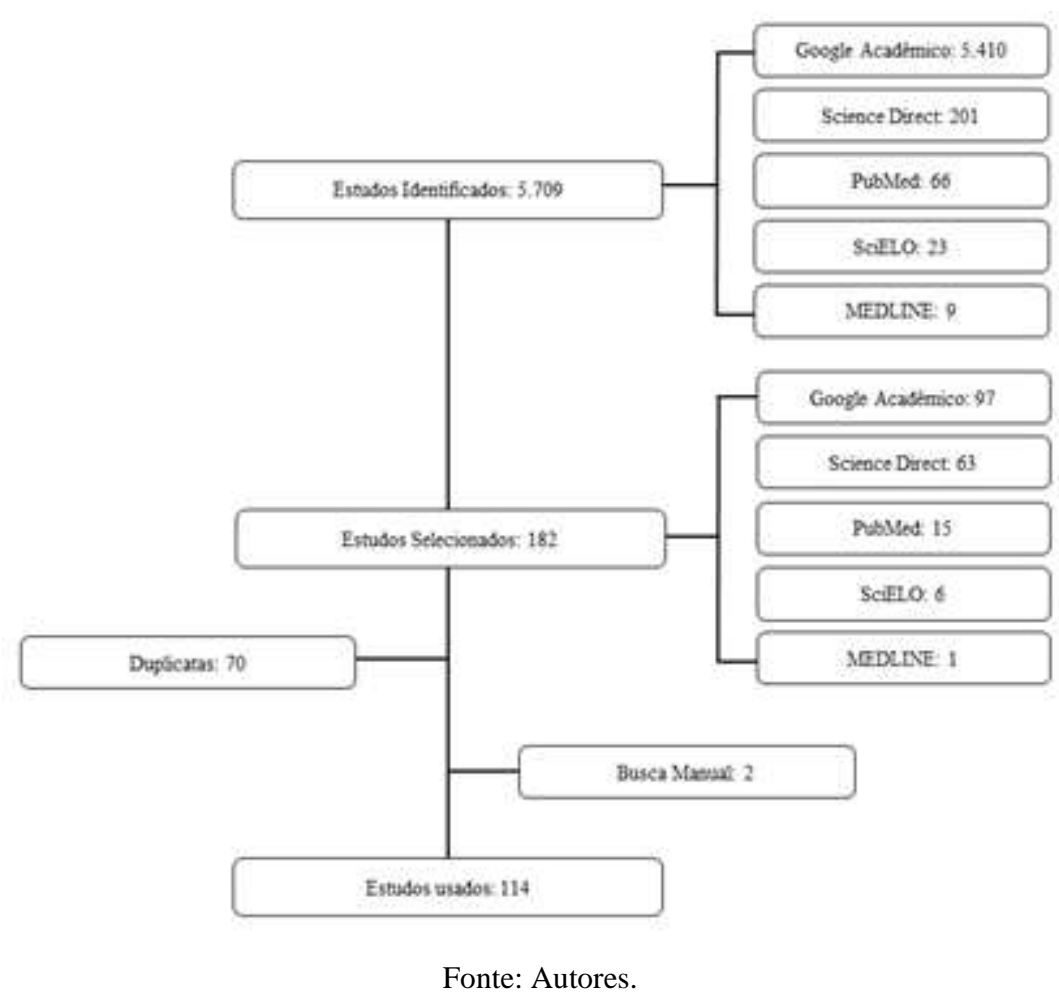

Os estudos selecionados mostram pesquisas de atividades biológicas in vivo e/ou in vitro de mais de 100 plantas, sendo as atividades mais pesquisadas a anti-helmíntica (48), antimicrobiana (36), seguida de atividade acaricida (24). Em menor número foram estudadas as atividades antiviral (3) antitumoral (1) e cicatrizante (1). Na tabela 1 são mostrados todos os estudos biológicos (in vitro e in vivo) realizados com extratos, frações ou compostos isolados, bem como as respectivas plantas e suas referências. 
Research, Society and Development, v. 10, n. 8, e46710817223, 2021

(CC BY 4.0) | ISSN 2525-3409 | DOI: http://dx.doi.org/10.33448/rsd-v10i8.17223

Tabela 1: Plantas medicinais usadas na medicina veterinária no Brasil no período de 2000 a 2020.

\begin{tabular}{|c|c|c|c|c|c|c|c|c|c|}
\hline Autores & Espécie & Nome vulgar & $\begin{array}{c}\text { Parte } \\
\text { utilizada }\end{array}$ & Substância & $\begin{array}{l}\text { Constituintes } \\
\text { majoritários }\end{array}$ & Atividade & $\begin{array}{r}\text { Espécie } \\
\text { animal }\end{array}$ & Modelo & Resultados \\
\hline $\begin{array}{l}\text { Assis et al., } \\
2003\end{array}$ & $\begin{array}{l}\text { Spigelia anthelmia Linn. } \\
\text { (Loganiaceae) }\end{array}$ & $\begin{array}{c}\text { Erva- } \\
\text { lombrigueira }\end{array}$ & $\begin{array}{l}\text { Partes } \\
\text { aéreas }\end{array}$ & $\begin{array}{c}\text { Extratos hexânico, } \\
\text { clorofórmico, } \\
\text { metanólico, } \\
\text { acetato de etila }\end{array}$ & NR & Anti-helmíntica & Ovina & In vitro & $\begin{array}{c}\text { Alta } \\
\text { atividade }\end{array}$ \\
\hline $\begin{array}{c}\text { Schmitt et al., } \\
2003 \\
\end{array}$ & $\begin{array}{c}\text { Bryophyllum pinnatum } \\
\text { (Crassulaceae) }\end{array}$ & $\begin{array}{l}\text { Folha-da- } \\
\text { fortuna }\end{array}$ & Folhas & Decocto & NR & Antibacteriana & $\begin{array}{c}\text { Canina } \\
\text { Suína } \\
\end{array}$ & In vitro & $\begin{array}{c}\text { Baixa } \\
\text { atividade }\end{array}$ \\
\hline \multirow{3}{*}{$\begin{array}{l}\text { Nogueira et } \\
\text { al., } 2006\end{array}$} & $\begin{array}{c}\text { Cucurbita sp. } \\
\text { (Cucurbitaceae) }\end{array}$ & Abóbora & Semente & \multirow{3}{*}{$\begin{array}{c}\text { Substâncias } \\
\text { trituradas e diluídas } \\
\text { em água }\end{array}$} & \multirow{3}{*}{ NR } & \multirow{3}{*}{ Anti-helmíntica } & \multirow{3}{*}{ Caprina } & \multirow{3}{*}{ In vivo } & \multirow{3}{*}{$\begin{array}{l}\text { Nenhuma } \\
\text { atividade }\end{array}$} \\
\hline & $\begin{array}{c}\text { Operculina sp } \\
\text { (Convolvulaceae) }\end{array}$ & $\begin{array}{l}\text { Batata-de- } \\
\text { purga }\end{array}$ & Raiz & & & & & & \\
\hline & $\begin{array}{c}\text { Azadirachta indica } \\
\text { (Meliaceae) }\end{array}$ & Neem & Frutos & & & & & & \\
\hline Martins, 2006 & $\begin{array}{c}\text { Cymbopogon winterianus } \\
\text { (Poaceae) }\end{array}$ & $\begin{array}{l}\text { Citronela de } \\
\text { Java }\end{array}$ & Folhas & Óleo essencial & $\begin{array}{l}\text { Citronelal } \\
\text { Geraniol } \\
\text { Citronelol }\end{array}$ & Acaricida & Bovina & In vitro & $\begin{array}{c}\text { Alta } \\
\text { atividade } \\
\text { para } \\
\text { citronelal e } \\
\text { geraniol }\end{array}$ \\
\hline \multirow{3}{*}{$\begin{array}{c}\text { Almeida et al., } \\
2007\end{array}$} & $\begin{array}{c}\text { Momordica charantia } \\
\text { (Cucurbitaceae) }\end{array}$ & $\begin{array}{c}\text { Melão de São } \\
\text { Caetano } \\
\end{array}$ & Folhas & \multirow{3}{*}{$\begin{array}{c}\text { Farelo das partes } \\
\text { desidratadas }\end{array}$} & \multirow{3}{*}{ NR } & \multirow{3}{*}{ Anti-helmíntico } & \multirow{3}{*}{ Caprina } & \multirow{3}{*}{ In vivo } & \multirow{3}{*}{$\begin{array}{c}\text { Alta } \\
\text { atividade }\end{array}$} \\
\hline & $\begin{array}{l}\text { Cucurbita pepo } \\
\text { (Cucurbitaceae) }\end{array}$ & Jerimum & Sementes & & & & & & \\
\hline & $\begin{array}{c}\text { Operculina hamiltonii } \\
\text { (Convolvulaceae ) }\end{array}$ & $\begin{array}{c}\text { Batata de } \\
\text { purga }\end{array}$ & Raízes & & & & & & \\
\hline \multirow{2}{*}{$\begin{array}{l}\text { Camurça- } \\
\text { Vasconcelos } \\
\text { et al., } 2007\end{array}$} & $\begin{array}{l}\text { Croton zehntneri } \\
\text { (Euphorbiaceae) }\end{array}$ & Canela brava & Folhas & \multirow{2}{*}{$\begin{array}{c}\text { Óleo essencial, anetol } \\
\text { e timol }\end{array}$} & $\begin{array}{c}\text { Anetol } \\
\text { Anisaldeído } \\
\text { Estragol } \\
\end{array}$ & \multirow{2}{*}{ Anti-helmíntica } & \multirow{2}{*}{$\begin{array}{c}\text { Ovina } \\
\text { Caprina }\end{array}$} & \multirow{2}{*}{$\begin{array}{l}\text { In vitro } \\
\text { In vivo }\end{array}$} & \multirow{2}{*}{$\begin{array}{c}\text { Alta } \\
\text { atividade }\end{array}$} \\
\hline & $\begin{array}{l}\text { Lippia sidoides } \\
\text { (Verbenaceae) }\end{array}$ & $\begin{array}{l}\text { Alecrim- } \\
\text { pimenta }\end{array}$ & Folhas & & $\begin{array}{c}\text { Timol, } \\
\text { Cariofileno }\end{array}$ & & & & \\
\hline $\begin{array}{c}\text { Chagas et al., } \\
2008 \\
\end{array}$ & $\begin{array}{c}\text { Azadirachta indica } \\
\text { (Meliaceae) }\end{array}$ & Neem & Folhas & In natura & NR & Anti-helmíntico & Ovina & In vivo & $\begin{array}{l}\text { Nenhuma } \\
\text { atividade }\end{array}$ \\
\hline \multirow{3}{*}{$\begin{array}{l}\text { Fontenelle et } \\
\text { al., } 2008\end{array}$} & $\begin{array}{l}\text { Croton zehntneri } \\
\text { (Euphorbiaceae) }\end{array}$ & Canela brava & Folhas & Óleo essencial & Estragol, anetol & \multirow{3}{*}{ Antifúngica } & \multirow{3}{*}{ Roedores } & \multirow{3}{*}{$\begin{array}{l}\text { In vivo } \\
\text { In vitro }\end{array}$} & \multirow{3}{*}{$\begin{array}{c}\text { Alta } \\
\text { atividade }\end{array}$} \\
\hline & $\begin{array}{c}\text { Croton nepetaefolius } \\
\text { (Euphorbiaceae) }\end{array}$ & Canelinha & Folhas & Óleo essencial & $\begin{array}{c}\text { Metil-eugenol } \\
\text { Biciclogermacreno } \\
\end{array}$ & & & & \\
\hline & $\begin{array}{c}\text { Croton argyrophylloides } \\
\text { (Euphorbiaceae) }\end{array}$ & Marmeleiro & Folhas & Óleo essencial & $\begin{array}{c}\text { Espatulenol e } \\
\text { biciclogermacreno }\end{array}$ & & & & \\
\hline $\begin{array}{l}\text { Olivo et al., } \\
2008\end{array}$ & $\begin{array}{c}\text { Cymbopogon nardus } \mathrm{L} . \\
\text { (Poaceae) }\end{array}$ & Citronela & Folhas & Óleo essencial & $\begin{array}{c}\text { Citronelal } \\
\text { Citronelol } \\
\text { Geraniol } \\
\end{array}$ & Acaricida & Bovina & In vitro & $\begin{array}{c}\text { Alta } \\
\text { atividade }\end{array}$ \\
\hline \multirow{3}{*}{$\begin{array}{c}\text { Schuch et al., } \\
2008 \mathrm{a}\end{array}$} & $\begin{array}{c}\text { Baccharis trimera } \\
\text { (Asteraceae) }\end{array}$ & Carqueja & $\begin{array}{c}\text { Folhas e } \\
\text { Talos }\end{array}$ & \multirow{3}{*}{$\begin{array}{c}\text { Extrato hidroalcoólico } \\
\text { e decocto }\end{array}$} & \multirow{3}{*}{ NR } & \multirow{3}{*}{ Antisséptica } & \multirow{3}{*}{ Bovina } & \multirow{3}{*}{ In vitro } & \multirow{3}{*}{$\begin{array}{c}\text { Alta } \\
\text { atividade }\end{array}$} \\
\hline & $\begin{array}{c}\text { Eucalyptus ssp } \\
\text { Labill } \\
\text { (Myrtaceae) } \\
\end{array}$ & Eucalipto & $\begin{array}{c}\text { Folhas e } \\
\text { Talos }\end{array}$ & & & & & & \\
\hline & $\begin{array}{c}\text { Tagetes minuta } \\
\text { (Asteraceae) }\end{array}$ & Chinchilho & $\begin{array}{c}\text { Folhas e } \\
\text { Talos }\end{array}$ & & & & & & \\
\hline \multirow{3}{*}{$\begin{array}{l}\text { Schuch et al., } \\
2008 \text { b }\end{array}$} & Baccharis trimera & Carqueja & $\begin{array}{c}\text { Folhas e } \\
\text { Talos } \\
\end{array}$ & & & & & & Alta \\
\hline & $\begin{array}{c}\text { Bidens pilosa } \\
\text { (Asteraceae) }\end{array}$ & Picão-preto & $\begin{array}{c}\text { Folhas e } \\
\text { Talos }\end{array}$ & $\begin{array}{l}\text { Extratos } \\
\text { hidroalcoólico e }\end{array}$ & NR & Antifúngica & NR & In vitro & $\begin{array}{l}\text { Atıvidade } \\
\text { para } B .\end{array}$ \\
\hline & $\begin{array}{c}\text { Eucalyptus spp. } \\
\text { (Myrtaceae) }\end{array}$ & Eucalipto & $\begin{array}{c}\text { Folhas e } \\
\text { Talos }\end{array}$ & & & & & & punctatum \\
\hline
\end{tabular}


Research, Society and Development, v. 10, n. 8, e46710817223, 2021

(CC BY 4.0) | ISSN 2525-3409 | DOI: http://dx.doi.org/10.33448/rsd-v10i8.17223

\begin{tabular}{|c|c|c|c|c|c|c|c|c|c|}
\hline & $\begin{array}{c}\text { Polygonum punctatum } \\
\text { (Polygonaceae) }\end{array}$ & Erva de bicho & $\begin{array}{c}\text { Folhas e } \\
\text { Talos }\end{array}$ & & & & & & \\
\hline & $\begin{array}{c}\text { Tagetes minuta } \\
\text { (Asteraceae) }\end{array}$ & Chinchilho & $\begin{array}{c}\text { Folhas e } \\
\text { Talos } \\
\end{array}$ & & & & & & \\
\hline \multirow{4}{*}{$\begin{array}{l}\text { Broglio- } \\
\text { Micheletti } \\
\text { et al., } 2009\end{array}$} & $\begin{array}{c}\text { Azadiracta indica } \\
\text { (Meliaceae) }\end{array}$ & Neem & Folhas & \multirow{4}{*}{$\begin{array}{c}\text { Extrato etanólico e } \\
\text { hexânico }\end{array}$} & \multirow{4}{*}{ NR } & \multirow{4}{*}{ Acaricida } & \multirow{4}{*}{ Bovina } & \multirow{4}{*}{ In vitro } & \multirow{4}{*}{$\begin{array}{c}\text { Alta } \\
\text { atividade }\end{array}$} \\
\hline & $\begin{array}{c}\text { Cymbopogon citratus } \\
\text { (Poaceae) }\end{array}$ & Capim-santo & Folhas & & & & & & \\
\hline & $\begin{array}{c}\text { Annona muricata } \\
\text { (Annonaceae) }\end{array}$ & Graviola & Semente & & & & & & \\
\hline & $\begin{array}{c}\text { Syzygium malaccensis } \\
\text { (Myrtaceae) }\end{array}$ & Jambo & Flores & & & & & & \\
\hline $\begin{array}{l}\text { Bezerra et al., } \\
2009\end{array}$ & $\begin{array}{c}\text { Mimosa tenuiflora } \\
\text { (Fabaceae) }\end{array}$ & Jurema preta & Cascas & Extrato etanólico & NR & Antibacteriana & Bovina & In vitro & $\begin{array}{c}\text { Alta } \\
\text { atividade }\end{array}$ \\
\hline $\begin{array}{l}\text { Nascimento et } \\
\text { al., } 2009\end{array}$ & $\begin{array}{c}\text { Mentha villosa } \\
\text { (Lamiaceae) }\end{array}$ & Hortelã & $\begin{array}{l}\text { Ramos e } \\
\text { folhas }\end{array}$ & Hidrolato & NR & Anti-helmíntica & Bovina & $\begin{array}{l}\text { In vitro } \\
\text { in vivo }\end{array}$ & $\begin{array}{c}\text { Alta } \\
\text { atividade } \\
\text { in vitro }\end{array}$ \\
\hline $\begin{array}{l}\text { Oliveira et al., } \\
2009\end{array}$ & $\begin{array}{c}\text { Cocos nucifera } \mathrm{L} . \\
\text { (Arecaceae) }\end{array}$ & $\begin{array}{l}\text { Coco-da- } \\
\text { Bahia }\end{array}$ & $\begin{array}{l}\text { Casca do } \\
\text { fruto verde }\end{array}$ & Acetato de etila & NR & Anti-helmíntica & Ovina & $\begin{array}{l}\text { In vivo e } \\
\text { in vitro }\end{array}$ & $\begin{array}{c}\text { Alta } \\
\text { atividade } \\
\text { in vitro }\end{array}$ \\
\hline \multirow[b]{2}{*}{$\begin{array}{c}\text { Pereira et al., } \\
\text { 2009a }\end{array}$} & $\begin{array}{c}\text { Mimosa tenuiflora } \\
\text { (Fabaceae) }\end{array}$ & Jurema preta & Casca & \multirow[b]{2}{*}{ Extrato etanólico } & \multirow[b]{2}{*}{ NR } & \multirow[b]{2}{*}{ Antibacteriana } & \multirow[b]{2}{*}{ Bubalina } & \multirow[b]{2}{*}{ In vitro } & $\begin{array}{c}\text { Alta } \\
\text { atividade }\end{array}$ \\
\hline & $\begin{array}{c}\text { Azadiracta indica } \\
\text { (Meliaceae) }\end{array}$ & Neem & Folhas & & & & & & $\begin{array}{c}\text { para } \\
\text { Jurema } \\
\text { preta }\end{array}$ \\
\hline \multirow{2}{*}{$\begin{array}{l}\text { Pereira et al., } \\
2009 \mathrm{~b}\end{array}$} & $\begin{array}{c}\text { Mimosa tenuiflora } \\
\text { (Fabaceae) }\end{array}$ & Jurema-preta & Casca & \multirow{2}{*}{ Extrato etanólico } & \multirow{2}{*}{ NR } & \multirow{2}{*}{ Antifúngica } & \multirow{2}{*}{ Bovina } & \multirow{2}{*}{ In vitro } & $\begin{array}{c}\text { Alta } \\
\text { atividade }\end{array}$ \\
\hline & $\begin{array}{c}\text { Azadiracta indica } \\
\text { (Meliaceae) }\end{array}$ & Neem & Folhas & & & & & & $\begin{array}{c}\text { Jurema } \\
\text { Preta } \\
\end{array}$ \\
\hline $\begin{array}{c}\text { Cordeiro et } \\
\text { al., } 2010 \\
\end{array}$ & $\begin{array}{c}\text { Momordica charantia } \\
\text { (Cucurbitaceae) }\end{array}$ & $\begin{array}{c}\text { Melão-de- } \\
\text { São-Caetano } \\
\end{array}$ & Folhas & Extrato etanólico & NR & Anti-helmíntica & Caprina & In vitro & $\begin{array}{c}\text { Alta } \\
\text { atividade } \\
\end{array}$ \\
\hline \multirow{5}{*}{$\begin{array}{l}\text { Lima et al., } \\
2010\end{array}$} & $\begin{array}{c}\text { Mimosa tenuiflora } \\
\text { (Fabaceae) }\end{array}$ & Jurema preta & Cascas & \multirow{5}{*}{$\begin{array}{c}\text { Extratos } \\
\text { hidroalcoólicos }\end{array}$} & \multirow{5}{*}{ NR } & \multirow{5}{*}{ Antibacteriana } & \multirow{5}{*}{ Ovina } & \multirow{5}{*}{ In vitro } & \multirow{5}{*}{$\begin{array}{c}\text { Alta } \\
\text { atividade } \\
\text { em todas as } \\
\text { plantas }\end{array}$} \\
\hline & $\begin{array}{c}\text { Mimosa arenosa } \\
\text { (Fabaceae) }\end{array}$ & $\begin{array}{c}\text { Jurema } \\
\text { vermelha }\end{array}$ & Cascas & & & & & & \\
\hline & $\begin{array}{c}\text { Anacardium occidentale } \\
\text { Linn } \\
\text { (Anacardiaceae) }\end{array}$ & Cajueiro & Cascas & & & & & & \\
\hline & $\begin{array}{c}\text { Parapiptadenia rigida } \\
\text { (Fabaceae) }\end{array}$ & $\begin{array}{c}\text { Angico } \\
\text { vermelho } \\
\end{array}$ & Cascas & & & & & & \\
\hline & $\begin{array}{c}\begin{array}{c}\text { Bumelia sartorum } \\
\text { (Sapotaceae) }\end{array} \\
\end{array}$ & Quixabeira & Cascas & & & & & & \\
\hline \multirow{5}{*}{$\begin{array}{l}\text { Nader et al., } \\
2010\end{array}$} & $\begin{array}{c}\text { Baccharis dracunculifolia } \\
\text { (Asteraceae) } \\
\end{array}$ & Vassourinha & Folha & \multirow{5}{*}{$\begin{array}{c}\text { Extratos metanólico, } \\
\text { hexânico e } \\
\text { clorofórmico }\end{array}$} & \multirow{5}{*}{ NR } & \multirow{5}{*}{ Antibacteriana } & \multirow{5}{*}{ Bovina } & \multirow{5}{*}{ In vitro } & \\
\hline & $\begin{array}{c}\text { Cochlospermum regium } \\
\text { (Bixaceae) }\end{array}$ & $\begin{array}{l}\text { Algodãozinho } \\
\text { do campo }\end{array}$ & $\begin{array}{c}\text { (Casca, } \\
\text { entrecasca e } \\
\text { cerne de } \\
\text { raiz) }\end{array}$ & & & & & & $\begin{array}{c}\text { Alta } \\
\text { atividade } \\
\text { para } \\
\text { Baccharis } \\
\text { dracunculif }\end{array}$ \\
\hline & $\begin{array}{c}\text { Croton antisyphiliticus } \\
\text { (Euphorbiaceae) }\end{array}$ & Pé de perdiz & Raiz & & & & & & $\begin{array}{l}\text { olia, } \\
\text { Croton }\end{array}$ \\
\hline & $\begin{array}{c}\text { Eugenia dysenterica } \\
\text { (Myrtaceae) }\end{array}$ & Cagaita & Folha & & & & & & antlsyphillti \\
\hline & $\begin{array}{c}\text { Lippia sidoides } \\
\text { (Verbenaceae) }\end{array}$ & $\begin{array}{l}\text { Alecrim } \\
\text { pimenta }\end{array}$ & Folha & & & & & & \\
\hline
\end{tabular}


Research, Society and Development, v. 10, n. 8, e46710817223, 2021

(CC BY 4.0) | ISSN 2525-3409 | DOI: http://dx.doi.org/10.33448/rsd-v10i8.17223

\begin{tabular}{|c|c|c|c|c|c|c|c|c|c|}
\hline $\begin{array}{l}\text { Oliveira et al., } \\
2010\end{array}$ & $\begin{array}{c}\text { Caesalpinia ferrea } \\
\text { (Fabaceae) }\end{array}$ & Pau-ferro & Casca & Pomada & NR & Cicatrizante & Caprina & In vivo & $\begin{array}{c}\text { Alta } \\
\text { atividade }\end{array}$ \\
\hline $\begin{array}{c}\text { Pivoto et al., } \\
2010 \\
\end{array}$ & $\begin{array}{c}\text { Tropaeolum majus } \\
\text { (Tropaeolaceae) }\end{array}$ & Capuchinha & $\begin{array}{c}\text { Parte aérea } \\
\text { e flores }\end{array}$ & $\begin{array}{l}\text { Extrato aquoso e } \\
\text { etanólico a } 70 \% \\
\end{array}$ & NR & Acaricida & Bovina & In vitro & $\begin{array}{c}\text { Alta } \\
\text { atividade }\end{array}$ \\
\hline $\begin{array}{l}\text { Silva et al., } \\
2010\end{array}$ & $\begin{array}{l}\text { Schinus terebinthifolius } \\
\text { (Anacardiaceae) }\end{array}$ & Aroeira & Folhas & Óleo essencial & $\begin{array}{c}\text { p-Cimen-7-ol, 9- } \\
\text { epi- }(E) \text { - } \\
\text { cariofileno, carvona } \\
\text { e verbenona }\end{array}$ & Antibacteriana & Canina & In vitro & $\begin{array}{c}\text { Alta } \\
\text { atividade }\end{array}$ \\
\hline $\begin{array}{l}\text { Buzzati et al., } \\
2011\end{array}$ & $\begin{array}{c}\text { Glechon spathulata } \\
\text { (Lamiaceae) }\end{array}$ & $\begin{array}{l}\text { Mangerona- } \\
\text { do-campo }\end{array}$ & Folhas & $\begin{array}{c}\text { Extrato hidroetanólico } \\
\text { e clorofórmico }\end{array}$ & NR & Acaricida & Bovina & In vitro & $\begin{array}{c}\text { Alta } \\
\text { atividade } \\
\text { para o } \\
\text { extrato } \\
\text { hidroetanóli } \\
\text { co } \\
\end{array}$ \\
\hline $\begin{array}{l}\text { Costa et al., } \\
2011\end{array}$ & $\begin{array}{c}\text { Cocos nucifera } \\
\text { (Arecaceae) }\end{array}$ & Coco-da-bahia & $\begin{array}{l}\text { Líquido da } \\
\text { casca do } \\
\text { coco verde }\end{array}$ & Extrato butanólico & NR & Anti-helmíntica & Ovina & In vitro & $\begin{array}{c}\text { Alta } \\
\text { atividade }\end{array}$ \\
\hline $\begin{array}{c}\text { Giglioti et al., } \\
2011 \\
\end{array}$ & $\begin{array}{c}\text { Azadirachta indica } \\
\text { (Meliaceae) }\end{array}$ & Neem & Sementes & Extrato etanólico & Azadiractina A & Acaricida & Bovina & In vitro & $\begin{array}{c}\text { Alta } \\
\text { atividade }\end{array}$ \\
\hline \multirow{2}{*}{$\begin{array}{l}\text { Brito-Junior et } \\
\text { al., } 2011\end{array}$} & $\begin{array}{c}\text { Operculina hamiltonii } \\
\text { (Convolvulaceae) }\end{array}$ & $\begin{array}{c}\text { Batata de } \\
\text { purga }\end{array}$ & Folhas & Extrato etanólico & \multirow{2}{*}{ NR } & \multirow{2}{*}{ Anti-helmíntica } & \multirow{2}{*}{ Caprina } & \multirow{2}{*}{ In vitro } & \multirow{2}{*}{$\begin{array}{c}\text { Alta } \\
\text { atividade }\end{array}$} \\
\hline & $\begin{array}{c}\text { Mormodica charantia } \\
\text { (Cucurbitaceae) }\end{array}$ & $\begin{array}{c}\text { Melão de São } \\
\text { Caetano }\end{array}$ & Folhas & Extrato etanólico & & & & & \\
\hline $\begin{array}{l}\text { Monteiro et } \\
\text { al., } 2011\end{array}$ & $\begin{array}{l}\text { Jatropha curcas } \\
\text { (Euphorbiaceae) }\end{array}$ & Pinhão-manso & Sementes & $\begin{array}{l}\text { Extrato hexânico, } \\
\text { acetato de etila e } \\
\text { etanólico }\end{array}$ & $\begin{array}{c}\text { Fitoesteroides, } \\
\text { taninos, } \\
\text { catequinas, } \\
\text { triterpenos } \\
\end{array}$ & Anti-helmíntica & Ovina & In vitro & $\begin{array}{l}\text { Moderada } \\
\text { atividade }\end{array}$ \\
\hline $\begin{array}{l}\text { Oliveira et al., } \\
2011\end{array}$ & $\begin{array}{c}\text { Myracrodruon urundeuva } \\
\text { (Anacardiaceae) }\end{array}$ & $\begin{array}{l}\text { Aroeira-do- } \\
\text { sertão }\end{array}$ & $\begin{array}{l}\text { Folha e } \\
\text { caule }\end{array}$ & Extrato & $\begin{array}{l}\text { Fenóis totais, } \\
\text { taninos, } \\
\text { ácido gálico }\end{array}$ & Anti-helmíntica & Ovina & In vitro & $\begin{array}{c}\text { Alta } \\
\text { atividade }\end{array}$ \\
\hline $\begin{array}{l}\text { Barros et al., } \\
\quad 2012\end{array}$ & $\begin{array}{c}\text { Guettarda angelica } \\
\text { (Rubiaceae) }\end{array}$ & $\begin{array}{l}\text { Angélica-do- } \\
\text { mato }\end{array}$ & $\begin{array}{l}\text { Raiz, folha } \\
\text { e semente }\end{array}$ & $\begin{array}{c}\text { Extratos } \\
\text { aquoso, metanólico, } \\
\text { hexânico, } \\
\text { acetato de etila }\end{array}$ & NR & Antiviral & Bovina & In vitro & $\begin{array}{l}\text { Moderada } \\
\text { atividade }\end{array}$ \\
\hline $\begin{array}{c}\text { Borges-do- } \\
\text { Santos et al., } \\
2012 \\
\end{array}$ & $\begin{array}{c}\text { Caesalpinia pyramidalis } \\
\text { (Fabaceae) }\end{array}$ & Catingueira & Folhas & Extrato aquoso & NR & Anti-helmíntica & Caprina & In vivo & $\begin{array}{l}\text { Moderada } \\
\text { atividade }\end{array}$ \\
\hline \multirow{2}{*}{$\begin{array}{c}\text { Fujimoto et } \\
\text { al., } 2012\end{array}$} & $\begin{array}{c}\text { Cucurbita maxima } \\
\text { (Curcubitaceae) }\end{array}$ & Abóbora & Sementes & Farelo & \multirow[t]{2}{*}{ NR } & \multirow[t]{2}{*}{ Anti-helmíntica } & \multirow[t]{2}{*}{ Peixes } & \multirow[t]{2}{*}{ In vivo } & \multirow{2}{*}{$\begin{array}{c}\text { Alta } \\
\text { atividade } \\
\text { para } \\
\text { sementes } \\
\text { de abóbora }\end{array}$} \\
\hline & $\begin{array}{c}\text { Carica papaya } \\
\text { (Caricaceae) }\end{array}$ & Mamão & Sementes & Farelo & & & & & \\
\hline $\begin{array}{l}\text { Katiki et al., } \\
2012\end{array}$ & $\begin{array}{c}\text { Cymbopogon schoenanthus } \\
\text { (Poaceae) }\end{array}$ & Capim camelo & NR & Óleo essencial & $\begin{array}{c}\text { Geraniol, } \\
\text { geranial, } \\
\text { neral }\end{array}$ & Anti-helmíntica & Ovina & In vivo & $\begin{array}{l}\text { Nenhuma } \\
\text { atividade }\end{array}$ \\
\hline \multirow{5}{*}{$\begin{array}{l}\text { Kaziyama et } \\
\text { al., } 2012\end{array}$} & $\begin{array}{c}\text { Mikania glomerata } \\
\text { (Asteraceae) }\end{array}$ & Guaco & Follhas & Extrato aquoso & \multirow{5}{*}{ NR } & \multirow{5}{*}{ Antiviral } & \multirow{5}{*}{$\begin{array}{c}\text { Suína } \\
\text { Bovina }\end{array}$} & \multirow{5}{*}{ In vitro } & \multirow{5}{*}{$\begin{array}{c}\text { Alta } \\
\text { atividade } \\
\text { para } \\
\text { Peumus } \\
\text { boldus } \\
\text { e Solanum } \\
\text { paniculatu } \\
m\end{array}$} \\
\hline & $\begin{array}{c}\text { Cymbopogon citratus } \\
\text { (Poaceae) }\end{array}$ & Capim Santo & Follhas & Extrato aquoso & & & & & \\
\hline & $\begin{array}{c}\text { Equisetum arvense } \\
\text { (Equisetaceae) }\end{array}$ & Cavalinha & Follhas & Extrato aquoso & & & & & \\
\hline & $\begin{array}{l}\text { Peumus boldus } \\
\text { (Monimiaceae) }\end{array}$ & $\begin{array}{l}\text { Boldo-do- } \\
\text { Chile }\end{array}$ & Folhas & Extrato etanólico & & & & & \\
\hline & Solanum paniculatum & Jurubeba & Folhas & Extrato aquoso & & & & & \\
\hline
\end{tabular}


Research, Society and Development, v. 10, n. 8, e46710817223, 2021

(CC BY 4.0) | ISSN 2525-3409 | DOI: http://dx.doi.org/10.33448/rsd-v10i8.17223

\begin{tabular}{|c|c|c|c|c|c|c|c|c|c|}
\hline & (Solanaceae) & & & & & & & & \\
\hline & $\begin{array}{c}\text { Malva sylvestris } \\
\text { (Malvaceae) }\end{array}$ & Malva & Folhas & Extrato aquoso & & & & & \\
\hline & $\begin{array}{c}\text { Piper umbellatun } \\
\text { (Piperaceae) }\end{array}$ & Pariparoba & Folhas & Extrato aquoso & & & & & \\
\hline & $\begin{array}{c}\text { Solidago microglossa } \\
\text { (Asteraceae) }\end{array}$ & Arnica & Folhas & Extrato aquoso & & & & & \\
\hline \multirow{4}{*}{$\begin{array}{l}\text { Macedo et al., } \\
2012\end{array}$} & $\begin{array}{c}\text { Alpinia zerumbet } \\
\text { (Zingiberaceae) }\end{array}$ & Cardamomo & Folhas & \multirow{4}{*}{ Decocção } & \multirow{4}{*}{$\begin{array}{l}\text { Taninos, } \\
\text { flavonoides }\end{array}$} & \multirow{4}{*}{ Anti-helmíntica } & \multirow{4}{*}{ Ovina } & \multirow{4}{*}{ In vitro } & \multirow{4}{*}{$\begin{array}{l}\text { Moderada } \\
\text { atividade }\end{array}$} \\
\hline & $\begin{array}{c}\text { Lantana camara } \\
\text { (Verbenaceae) }\end{array}$ & Camará & Folhas & & & & & & \\
\hline & $\begin{array}{c}\text { Mentha villosa } \\
\text { (Lamiaceae) }\end{array}$ & Hortelã & Folhas & & & & & & \\
\hline & $\begin{array}{c}\text { Tagetes minuta } \\
\text { (Asteraceae) }\end{array}$ & $\begin{array}{l}\text { Cravo-de- } \\
\text { defunto }\end{array}$ & Folhas & & & & & & \\
\hline $\begin{array}{l}\text { Pozzo et al., } \\
2012\end{array}$ & $\begin{array}{c}\text { Cinnamomum zeylanicum } \\
\text { (Lauraceae) }\end{array}$ & Canela & Folhas & $\begin{array}{l}\text { Óleo essencial e } \\
\text { fração trans- } \\
\text { cinnamaldeído } \\
\text { (Comercial) }\end{array}$ & Isoeugenol & Antibacteriana & $\begin{array}{l}\text { Bovina } \\
\text { Caprina }\end{array}$ & In vitro & $\begin{array}{c}\text { Alta } \\
\text { atividade } \\
\text { para a } \\
\text { Fração } \\
\text { trans- } \\
\text { cinnamalde } \\
\text { ído } \\
\end{array}$ \\
\hline $\begin{array}{c}\text { Santos et al., } \\
\text { 2012a } \\
\end{array}$ & $\begin{array}{c}\text { Cymbopogon nardus } \\
\text { (Poaceae) }\end{array}$ & Citronela & Comercial & Óleo e tintura & NR & Acaricida & Bovina & In vitro & $\begin{array}{l}\text { Nenhuma } \\
\text { atividade }\end{array}$ \\
\hline $\begin{array}{l}\text { Santos et al., } \\
2012 \mathrm{~b} \\
\end{array}$ & $\begin{array}{c}\text { Ocimum basilicum } \\
\text { (Lamiaceae) }\end{array}$ & Manjericão & Folhas & Óleo essencial & NR & Acaricida & Bovina & In vitro & $\begin{array}{c}\text { Alta } \\
\text { atividade }\end{array}$ \\
\hline $\begin{array}{c}\text { Silveira et al., } \\
2012 \\
\end{array}$ & $\begin{array}{c}\text { Agave sisalana } \\
\text { (Agavaceae) }\end{array}$ & Sisal & Folhas & Extrato & NR & Anti-helmíntica & $\begin{array}{c}\text { Caprina } \\
\text { Ovina }\end{array}$ & In vitro & $\begin{array}{c}\text { Muita } \\
\text { atividade }\end{array}$ \\
\hline \multirow{3}{*}{$\begin{array}{l}\text { Andrade et al., } \\
2013\end{array}$} & $\begin{array}{c}\text { Momordica charantia } \\
\text { (Cucurbitaceae) }\end{array}$ & $\begin{array}{c}\text { Melão de São } \\
\text { Caetano }\end{array}$ & NR & \multirow{3}{*}{ Extrato etanólico } & \multirow{3}{*}{ NR } & \multirow{3}{*}{ Acaricida } & \multirow{3}{*}{ Canina } & \multirow{3}{*}{ In vitro } & \multirow{3}{*}{$\begin{array}{c}\text { Alta } \\
\text { atividade } \\
\text { Para melão } \\
\text { de São } \\
\text { Caetano e } \\
\text { capim santo }\end{array}$} \\
\hline & $\begin{array}{c}\text { Azadirachta indica } \\
\text { (Meliaceae) }\end{array}$ & Neem & NR & & & & & & \\
\hline & $\begin{array}{c}\text { Cymbopogin citratus } \\
\text { (Poaceae) }\end{array}$ & Capim Santo & NR & & & & & & \\
\hline $\begin{array}{c}\text { Brito; } \\
\text { Fernandes, } \\
2013 \\
\end{array}$ & $\begin{array}{c}\text { Morinda citrifolia } \\
\text { (Rubiaceae) }\end{array}$ & Noni & Frutos & $\begin{array}{c}\text { Extrato aquoso } \\
\text { etanólico }\end{array}$ & NR & Anti-helmíntica & Aves & $\begin{array}{l}\text { In vitro } \\
\text { In vivo }\end{array}$ & $\begin{array}{c}\text { Alta } \\
\text { atividade } \\
\text { in vitro } \\
\end{array}$ \\
\hline $\begin{array}{l}\text { Cruz et al., } \\
2013\end{array}$ & $\begin{array}{l}\text { Lippia gracilis } \\
\text { (Verbenaceae) }\end{array}$ & $\begin{array}{l}\text { Alecrim-do- } \\
\text { serrote }\end{array}$ & Folhas & $\begin{array}{c}\text { Óleo Essencial } \\
\text { Componentes } \\
\text { Carvacrol e Timol } \\
\end{array}$ & $\begin{array}{l}\text { Carvacrol } \\
\text { Timol }\end{array}$ & Acaricida & Bovina & In vitro & $\begin{array}{c}\text { Alta } \\
\text { atividade }\end{array}$ \\
\hline $\begin{array}{l}\text { Domingues et } \\
\text { al., } 2013\end{array}$ & $\begin{array}{c}\text { Ananas comosus } \\
\text { (Bromeliaceae) }\end{array}$ & Abacaxi & Fruto & Extrato aquoso & NR & Anti-helmíntica & Ovina & $\begin{array}{l}\text { In vitro } \\
\text { In vivo }\end{array}$ & $\begin{array}{c}\text { Moderada } \\
\text { atividade } \\
\text { in vitro } \\
\end{array}$ \\
\hline $\begin{array}{l}\text { Feitosa et al., } \\
2013\end{array}$ & $\begin{array}{l}\text { Cucurbita pepo } \\
\text { (Cucurbitaceae) }\end{array}$ & Abóbora & Semente & Farelo & NR & Anti-helmíntica & Aves & In vivo & $\begin{array}{c}\text { Alta } \\
\text { atividade } \\
\text { para } \\
\text { semente de } \\
\text { abóbora } \\
\end{array}$ \\
\hline $\begin{array}{l}\text { Ferreira et al., } \\
2013\end{array}$ & $\begin{array}{c}\text { Annona muricata } \mathrm{L} . \\
\text { (Annonaceae) }\end{array}$ & Graviola & Folhas & Extrato aquoso & $\begin{array}{l}\text { Compostos } \\
\text { fenólicos }\end{array}$ & Anti-helmíntica & Ovina & In vitro & $\begin{array}{c}\text { Alta } \\
\text { atividade }\end{array}$ \\
\hline $\begin{array}{c}\text { Macedo et al., } \\
2013 \\
\end{array}$ & $\begin{array}{c}\text { Lantana camara } \\
\text { (Verbenaceae) }\end{array}$ & Camará & NR & Óleo essencial & NR & Anti-helmíntica & Ovina & In vitro & $\begin{array}{c}\text { Alta } \\
\text { atividade } \\
\end{array}$ \\
\hline $\begin{array}{l}\text { Mesquita et } \\
\text { al., } 2013\end{array}$ & $\begin{array}{c}\text { Eucalyptus staigeriana } \\
\text { (Myrtaceae) }\end{array}$ & Eucalipto & Folhas & $\begin{array}{l}\text { Óleo essencial } \\
\text { encapsulado }\end{array}$ & $\begin{array}{c}\text { Limoneno, } \\
\text { cineol, } \\
o \text {-cimeno }\end{array}$ & Anti-helmíntica & Ovina & $\begin{array}{l}\text { In vitro } \\
\text { In vivo }\end{array}$ & $\begin{array}{c}\text { Alta } \\
\text { atividade }\end{array}$ \\
\hline $\begin{array}{l}\text { Mota et al., } \\
2013\end{array}$ & $\begin{array}{c}\text { Syzygium cumini } \\
\text { (Myrtaceae) }\end{array}$ & Jamelão & Folhas & $\begin{array}{c}\text { Extrato } \\
\text { hidroalcoólico }\end{array}$ & NR & Antibacteriana & Bovina & In vitro & $\begin{array}{c}\text { Alta } \\
\text { atividade }\end{array}$ \\
\hline
\end{tabular}


Research, Society and Development, v. 10, n. 8, e46710817223, 2021

(CC BY 4.0) | ISSN 2525-3409 | DOI: http://dx.doi.org/10.33448/rsd-v10i8.17223

\begin{tabular}{|c|c|c|c|c|c|c|c|c|c|}
\hline $\begin{array}{c}\text { Hocayen; } \\
\text { Pimenta, } 2013\end{array}$ & $\begin{array}{l}\text { Ocimum gratissimum } \\
\text { (Lamiaceae) }\end{array}$ & Alfavaca & Folhas & Óleo essencial & NR & Acaricida & Bovina & In vitro & $\begin{array}{c}\text { Alta } \\
\text { atividade } \\
\text { hidrolato de } \\
\text { alfavaca } \\
\end{array}$ \\
\hline $\begin{array}{l}\text { Righi et al., } \\
2013\end{array}$ & $\begin{array}{c}\text { Croton sphaerogynus } \\
\text { (Euphorbiaceae) }\end{array}$ & Sacaca & Folhas & $\begin{array}{c}\text { Extrato } \\
\text { diclorometânico }\end{array}$ & $\begin{array}{c}\text { Abietanos, } \\
\text { podocarpenos e } \\
\text { furano do tipo } \\
\text { clerodano, } \\
\text { diterpenos. }\end{array}$ & Acaricida & Bovina & In vitro & $\begin{array}{c}\text { Alta } \\
\text { atividade }\end{array}$ \\
\hline $\begin{array}{l}\text { Santos et al., } \\
2013 \\
\end{array}$ & $\begin{array}{c}\text { Chenopodium ambrosioides } \\
\text { (Poaceae) }\end{array}$ & Mastruz & NR & Tintura & NR & Acaricida & Bovina & In vitro & $\begin{array}{c}\text { Alta } \\
\text { atividade }\end{array}$ \\
\hline \multirow{2}{*}{$\begin{array}{l}\text { Silva et al., } \\
2013\end{array}$} & $\begin{array}{c}\text { Cecropia hololeuca } \\
\text { (Urticaceae) }\end{array}$ & Embaúba & Folhas & \multirow{2}{*}{$\begin{array}{l}\text { Extrato aquoso e } \\
\text { extrato desidratado }\end{array}$} & \multirow{2}{*}{ NR } & \multirow{2}{*}{ Anti-helmíntica } & \multirow{2}{*}{ Caprina } & \multirow{2}{*}{ In vitro } & \multirow{2}{*}{$\begin{array}{l}\text { Nenhuma } \\
\text { atividade }\end{array}$} \\
\hline & $\begin{array}{c}\text { Musa sp } \\
\text { (Musaceae) }\end{array}$ & Bananeira & Folhas & & & & & & \\
\hline $\begin{array}{l}\text { Ziech et al., } \\
2013\end{array}$ & $\begin{array}{c}\text { Copaifera reticulata } \\
\text { (Fabaceae) }\end{array}$ & Copaíba & Oleorresina & $\begin{array}{c}\text { Extrato } \\
\text { semi-sólido }\end{array}$ & $\begin{array}{c}\beta \text {-cariofileno, } \beta \text { - } \\
\text { bisaboleno } \\
\text { (E)-bergamoteno } \\
\end{array}$ & Antibacteriana & Canina & In vitro & $\begin{array}{c}\text { Alta } \\
\text { atividade }\end{array}$ \\
\hline $\begin{array}{c}\text { Agnolin et al., } \\
2014 \\
\end{array}$ & $\begin{array}{c}\text { Cymbopogum flexuosus } \\
\text { (Poaceae) }\end{array}$ & Capim limão & Parte aérea & Óleo essencial & NR & Acaricida & Bovina & $\begin{array}{l}\text { In vitro } \\
\text { In vivo }\end{array}$ & $\begin{array}{l}\text { Moderada } \\
\text { atividade }\end{array}$ \\
\hline \multirow{2}{*}{$\begin{array}{c}\text { Almeida et al., } \\
2014\end{array}$} & $\begin{array}{c}\text { Artemisia аппиа } \\
\text { (Asteraceae) }\end{array}$ & $\begin{array}{l}\text { Artemísia- } \\
\text { chinesa }\end{array}$ & Folhas & & & Anti-helmíntico & & & \\
\hline & $\begin{array}{l}\text { Curcuma longa } \\
\text { (Zingiberaceae) }\end{array}$ & $\begin{array}{l}\text { Açafrão-da- } \\
\text { terra }\end{array}$ & Folhas & Extrato etanólico & NR & 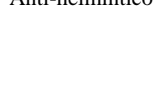 & Aves & In vivo & conclusivo \\
\hline & $\begin{array}{c}\text { Cymbopogon winterianus } \\
\text { (Poaceae) }\end{array}$ & Citronela & Folhas & Óleo essencial & $\begin{array}{l}\text { Citronelal, acetato } \\
\text { de citronelal, } \\
\text { acetato de geranila, } \\
\text { germacreno D, } \\
\alpha \text {-cadineno, } \\
\alpha \text {-limoneno } \\
\beta \text {-citral }\end{array}$ & \multirow{2}{*}{ Acaricida } & \multirow{2}{*}{ Bovina } & \multirow{2}{*}{ In vitro } & \multirow{2}{*}{$\begin{array}{c}\text { Alta } \\
\text { atividade } \\
\text { para óleo } \\
\text { essencial } \\
\text { do cravo }\end{array}$} \\
\hline $\begin{array}{l}\text { Melo et al., } \\
2014\end{array}$ & $\begin{array}{c}\text { Syzygium aromaticum } \\
\text { (Mytaceae) }\end{array}$ & $\begin{array}{l}\text { Cravo-da- } \\
\text { índia }\end{array}$ & Frutos & Óleo essencial & $\begin{array}{l}\text { Eugenol, acetato de } \\
\text { eugenila, } \beta \text { - } \\
\text { cariofileno e óxido } \\
\text { de cariofileno }\end{array}$ & & & & \\
\hline $\begin{array}{l}\text { Moreira et al., } \\
2014 \\
\end{array}$ & $\begin{array}{c}\text { Punica granatum } \\
\text { (Punicaceae) } \\
\end{array}$ & Romã & Casca & Extrato hidroalcoólico & NR & Antibacteriana & Bovina & In vitro & $\begin{array}{c}\text { Alta } \\
\text { atividade }\end{array}$ \\
\hline $\begin{array}{c}\text { Ribeiro et al., } \\
2014 \\
\end{array}$ & $\begin{array}{c}\text { Jatropha mollissima } \\
\text { (Euphorbiaceae) }\end{array}$ & Pinhão-bravo & Caule & Extrato etanólico & NR & Anti-helmíntica & Ovina & $\begin{array}{l}\text { In vivo } \\
\text { In vitro }\end{array}$ & $\begin{array}{c}\text { Alta } \\
\text { atividade }\end{array}$ \\
\hline $\begin{array}{l}\text { Dantas et al., } \\
2015\end{array}$ & $\begin{array}{l}\text { Neoglaziovia variegata } \\
\text { (Bromeliaceae) }\end{array}$ & Caroá & $\begin{array}{c}\text { Folhas e } \\
\text { partes } \\
\text { aéreas }\end{array}$ & $\begin{array}{c}\text { Frações de etanol, } \\
\text { hexano, clorofórmio e } \\
\text { acetato de etila }\end{array}$ & NR & Acaricida & Bovina & In vitro & $\begin{array}{c}\text { Alta } \\
\text { atividade }\end{array}$ \\
\hline $\begin{array}{c}\text { Gregory et al., } \\
2015 \\
\end{array}$ & $\begin{array}{c}\text { Musa spp. } \\
\text { (Musaceae) }\end{array}$ & Bananeira & $\begin{array}{l}\text { Folhas } \\
\text { secas }\end{array}$ & Farelo & NR & Anti-helmíntica & Ovelhas & In vivo & $\begin{array}{c}\text { Alta } \\
\text { atividade }\end{array}$ \\
\hline \multirow{2}{*}{$\begin{array}{l}\text { Hashimoto et } \\
\text { al., } 2015\end{array}$} & $\begin{array}{c}\text { Lippia sidoides } \\
\text { (Verbenaceae) }\end{array}$ & $\begin{array}{l}\text { Alecrin- } \\
\text { pimenta }\end{array}$ & Folhas & Óleo essencial & Timol e $p$-cimeno & \multirow{2}{*}{ Anti-helmíntico } & \multirow{2}{*}{ Peixe } & \multirow{2}{*}{ In vitro } & \multirow{2}{*}{$\begin{array}{c}\text { Alta } \\
\text { atividade }\end{array}$} \\
\hline & $\begin{array}{c}\text { Mentha piperita } \\
\text { (Lamiaceae) }\end{array}$ & $\begin{array}{l}\text { Hortelã- } \\
\text { pimenta }\end{array}$ & Folhas & Óleo essencial & Mentol & & & & \\
\hline $\begin{array}{l}\text { Peixoto et al., } \\
2015\end{array}$ & $\begin{array}{c}\text { Hymenaea martiana } \\
\text { (Fabaceae) }\end{array}$ & Jatobá & Cascas & $\begin{array}{c}\text { Extrato etanólico, } \\
\text { hexânico, } \\
\text { clorofórmico, acetato } \\
\text { de etila }\end{array}$ & $\begin{array}{c}\text { Compostos } \\
\text { fenólicos na fração } \\
\text { clorofórmica e } \\
\text { acetato de etila }\end{array}$ & Antibacteriana & NR & In vitro & $\begin{array}{c}\text { Alta } \\
\text { atividade }\end{array}$ \\
\hline $\begin{array}{l}\text { Soares et al., } \\
\quad 2015\end{array}$ & $\begin{array}{c}\text { Momordica charantia } \\
\text { (Cucurbitaceae) }\end{array}$ & $\begin{array}{l}\text { Melão de São } \\
\text { Caetano }\end{array}$ & $\begin{array}{l}\text { Folhas, } \\
\text { frutos, }\end{array}$ & Extrato etanólico & $\begin{array}{l}\text { Alcaloides } \\
\text { Esteroides } \\
\text { Saponinas } \\
\end{array}$ & Antifúngica & $\begin{array}{l}\text { Canina } \\
\text { Felina }\end{array}$ & $\begin{array}{l}\text { In vitro } \\
\text { In vitro }\end{array}$ & $\begin{array}{c}\text { Alta } \\
\text { atividade }\end{array}$ \\
\hline
\end{tabular}


Research, Society and Development, v. 10, n. 8, e46710817223, 2021

(CC BY 4.0) | ISSN 2525-3409 | DOI: http://dx.doi.org/10.33448/rsd-v10i8.17223

\begin{tabular}{|c|c|c|c|c|c|c|c|c|c|}
\hline & & & $\begin{array}{c}\text { folhas e } \\
\text { caule }\end{array}$ & & & & & & \\
\hline & $\begin{array}{c}\text { Calotropis procera } \\
\text { (Apocynaceae) }\end{array}$ & Flor-de-seda & Folhas & & NR & & & & $\begin{array}{r}\text { Nenhuma } \\
\text { atividade } \\
\end{array}$ \\
\hline & $\begin{array}{l}\text { Peschiera affinis } \\
\text { (Cucurbitaceae) }\end{array}$ & Grão-de-galo & Caule & & $\beta$-Sitosterol e lupeol & & & & $\begin{array}{c}\text { Alta } \\
\text { atividade }\end{array}$ \\
\hline & $\begin{array}{c}\text { Piper tuberculatum } \\
\text { (Piperaceae) }\end{array}$ & Pimenta longa & Folhas & & $\begin{array}{l}(E) \text {-Cariofileno, } \\
\text { germacreno D e } \\
\text { pineno }\end{array}$ & & & & $\begin{array}{c}\text { Alta } \\
\text { atividade }\end{array}$ \\
\hline & $\begin{array}{l}\text { Mangifera indica } \\
\text { (Anacardiaceae) }\end{array}$ & Manga & Folhas & Decocção & NR & & & & $\begin{array}{c}\text { Alta } \\
\text { atividade }\end{array}$ \\
\hline $\begin{array}{l}\text { Sprenger et } \\
\text { al., } 2015\end{array}$ & $\begin{array}{c}\text { Artemisia аппиа } \\
\text { (Asteraceae) }\end{array}$ & $\begin{array}{l}\text { Erva-de-São- } \\
\text { João }\end{array}$ & Folhas & Extrato hidroalcoólico & $\begin{array}{c}\text { Alcaloides, } \\
\text { catequinas, } \\
\text { esteroides, fenóis, } \\
\text { resinas, taninos e } \\
\text { triterpenos } \\
\end{array}$ & Anti-helmíntica & Aves & In vivo & $\begin{array}{l}\text { Alta } \\
\text { atividade }\end{array}$ \\
\hline $\begin{array}{l}\text { Almeida et al., } \\
\qquad 2016\end{array}$ & $\begin{array}{c}\text { Lippia origanoides Cham } \\
\text { (Verbenaceae) }\end{array}$ & $\begin{array}{l}\text { Alecrim } \\
\text { pimenta }\end{array}$ & Folhas & Óleo essencial & $\begin{array}{c}\text { Carvacrol, } p \text { - } \\
\text { cimeno, timilmetil } \\
\text { éter, cariofileno e y- } \\
\text { terpineno }\end{array}$ & Antisséptica & Bovina & In vitro & $\begin{array}{l}\text { Alta } \\
\text { atividade }\end{array}$ \\
\hline $\begin{array}{l}\text { Batista et al., } \\
2016\end{array}$ & $\begin{array}{l}\text { Schinus molle L } \\
\text { (Anacardiaceae) }\end{array}$ & Aroeira branca & $\begin{array}{l}\text { Folhas e } \\
\text { frutos }\end{array}$ & $\begin{array}{c}\text { Óleo essencial } \\
\text { Extratos hexânico, } \\
\text { metanólico, acetato de } \\
\text { etila }\end{array}$ & $\begin{array}{c}\text { Espatulenol, } \\
\text { cubenol, 4- } \\
\text { terpineol, mirtenal, } \\
\text { espatulenol } \\
\text { lupenona (Hexano) }\end{array}$ & Acaricida & $\begin{array}{l}\text { Canina } \\
\text { Felina }\end{array}$ & In vitro & $\begin{array}{c}\text { Alta } \\
\text { atividade }\end{array}$ \\
\hline $\begin{array}{l}\text { Cavalcante } \\
\text { et al., } 2016\end{array}$ & $\begin{array}{c}\text { Calotropis procera } \\
\text { (Apocynaceae) }\end{array}$ & Bombadeira & Latex & Extrato acetato de etila & $\begin{array}{c}\text { Acetato de } \\
\text { calotropenil, } \\
\text { calotropenil, e 1- } \\
\text { (2',5'- } \\
\text { dimetoxifenil)- } \\
\text { glicerol } \\
\end{array}$ & Anti-helmíntica & Ovina & In vitro & $\begin{array}{c}\text { Alta } \\
\text { atividade }\end{array}$ \\
\hline $\begin{array}{c}\text { Gomes et al., } \\
2016 \\
\end{array}$ & $\begin{array}{c}\text { Ziziphus joazeiro } \\
\text { (Rhamnaceae) }\end{array}$ & Juazeiro & Casca & $\begin{array}{c}\text { Extrato hidroetanólico, } \\
\text { hexânico, aquoso }\end{array}$ & Saponinas & Anti-helmíntica & Caprina & In vitro & $\begin{array}{c}\text { Alta } \\
\text { atividade }\end{array}$ \\
\hline $\begin{array}{l}\text { Morais-Costa } \\
\text { et al., } 2016\end{array}$ & $\begin{array}{l}\text { Piptadenia viridiflora } \\
\text { (Fabaceae) }\end{array}$ & Urucucu & Folhas & $\begin{array}{l}\text { Extrato aquoso e } \\
\text { etanólico }\end{array}$ & Tanino e flavonoide & Anti-helmíntica & Ovina & $\begin{array}{l}\text { In vitro } \\
\text { In vivo }\end{array}$ & $\begin{array}{c}\text { Alta } \\
\text { atividade } \\
\text { in vitro }\end{array}$ \\
\hline $\begin{array}{l}\text { Dantas et al., } \\
\qquad 2016\end{array}$ & $\begin{array}{c}\text { Amburana cearensis } \\
\text { (Fabaceae) }\end{array}$ & $\begin{array}{l}\text { Imburana-de } \\
\text { cheiro }\end{array}$ & Folhas & $\begin{array}{c}\text { Frações hexânica, } \\
\text { clorofórmica e acetato } \\
\text { de } \\
\text { etila }\end{array}$ & NR & Acaricida & Bovina & In vitro & $\begin{array}{c}\text { Alta } \\
\text { atividade } \\
\text { fração } \\
\text { hexanica } \\
\end{array}$ \\
\hline $\begin{array}{l}\text { Féboli et al., } \\
\qquad 2016\end{array}$ & $\begin{array}{l}\text { Opuntia ficus-indica } \\
\text { (Cactaceae) }\end{array}$ & $\begin{array}{l}\text { Figueira-da- } \\
\quad \text { índia }\end{array}$ & $\begin{array}{l}\text { Cladódios e } \\
\text { frutos }\end{array}$ & $\begin{array}{c}\text { Extratos } \\
\text { etanólico, } \\
\text { hexânico, } \\
\text { diclorometano e } \\
\text { acetato de etila } \\
\end{array}$ & NR & Anti-helmíntica & Ovina & In vitro & $\begin{array}{c}\text { Alta } \\
\text { atividade }\end{array}$ \\
\hline $\begin{array}{c}\text { Ferreira et al., } \\
2016 \\
\end{array}$ & $\begin{array}{c}\text { Thymus vulgaris L. } \\
\text { (Lamiaceae) }\end{array}$ & Tomilho & Folhas & Óleo essencial & $\begin{array}{c}\text { Timol } \\
\text { p-cimeno }\end{array}$ & Anti-helmíntica & Ovina & $\begin{array}{l}\text { In vivo e } \\
\text { in vitro }\end{array}$ & $\begin{array}{c}\text { Alta } \\
\text { atividade } \\
\end{array}$ \\
\hline $\begin{array}{l}\text { Soares et al., } \\
\quad 2016\end{array}$ & $\begin{array}{l}\text { Lippia sidoides } \\
\text { (Verbenaceae) }\end{array}$ & $\begin{array}{l}\text { Alecrim- } \\
\text { pimenta }\end{array}$ & $\begin{array}{c}\text { Folhas e } \\
\text { inflorescên } \\
\text { cias } \\
\end{array}$ & Óleo essencial & NR & Anti-helmíntica & Peixe & $\begin{array}{l}\text { In vivo } \\
\text { In vitro }\end{array}$ & $\begin{array}{c}\text { Alta } \\
\text { atividade } \\
\text { in vitro }\end{array}$ \\
\hline \multirow[t]{2}{*}{$\begin{array}{c}\text { Mendonça- } \\
\text { Lima et al., } \\
2016 \\
\end{array}$} & $\begin{array}{l}\text { Cratylia mollis } \\
\text { (Leguminosae) }\end{array}$ & Camaratuba & Folha & $\begin{array}{l}\text { Extrato aquoso } \\
\text { (decocção) }\end{array}$ & NR & Anti-helmíntica & Caprina & In vitro & $\begin{array}{c}\text { Alta } \\
\text { atividade }\end{array}$ \\
\hline & $\begin{array}{c}\text { Encholirium spectabile } \\
\text { (Bromeliaceae) }\end{array}$ & $\begin{array}{c}\text { Macambira de } \\
\text { flecha }\end{array}$ & NR & Extrato etanólico bruto & $\begin{array}{l}\text { Compostos } \\
\text { fenólicos, }\end{array}$ & Antibacteriana & $\begin{array}{l}\text { Ovina } \\
\text { caprina }\end{array}$ & In vitro & $\begin{array}{c}\text { Alta } \\
\text { atividade }\end{array}$ \\
\hline
\end{tabular}


Research, Society and Development, v. 10, n. 8, e46710817223, 2021

(CC BY 4.0) | ISSN 2525-3409 | DOI: http://dx.doi.org/10.33448/rsd-v10i8.17223

\begin{tabular}{|c|c|c|c|c|c|c|c|c|c|}
\hline $\begin{array}{l}\text { Peixoto et al., } \\
2016\end{array}$ & $\begin{array}{c}\text { Bromelia laciniosa } \\
\text { (Bromeliaceae) }\end{array}$ & $\begin{array}{l}\text { Mcambira de } \\
\text { porco }\end{array}$ & NR & Extrato etanólico bruto & $\begin{array}{l}\text { flavonoides, } \\
\text { esteroides e }\end{array}$ & & Suína & & \\
\hline Sá et al., 2011 & $\begin{array}{c}\text { Neoglaziovia variegata } \\
\text { (Bromeliaceae) }\end{array}$ & Caroá & NR & Extrato etanólico bruto & & & & & \\
\hline Silva et al & $\begin{array}{c}\text { Amburana cearensis } \\
\text { (Fabaceae) }\end{array}$ & $\begin{array}{l}\text { Imburana de } \\
\text { cheiro }\end{array}$ & NR & Extrato etanólico bruto & & & & & \\
\hline 2014 & $\begin{array}{c}\text { Hymenaea martiana } \\
\text { (Fabaceae) }\end{array}$ & Jatobá & NR & Extrato etanólico bruto & & & & & \\
\hline $\begin{array}{c}\text { Fernandes et } \\
\text { al., } 2015\end{array}$ & $\begin{array}{c}\text { Selaginella convoluta } \\
\text { (Selaginellaceae) }\end{array}$ & Jericó & NR & Extrato etanólico bruto & & & & & \\
\hline $\begin{array}{l}\text { Pereira et al., } \\
2016\end{array}$ & $\begin{array}{c}\text { Momordica charantia } \\
\text { (Cucurbitaceae) }\end{array}$ & $\begin{array}{l}\text { Melão de São } \\
\text { Caetano }\end{array}$ & Folhas & $\begin{array}{c}\text { Extrato bruto, } \\
\text { frações hexânica, } \\
\text { diclorometano, } \\
\text { butanólica e aquosa }\end{array}$ & Quercetina & Anti-helmíntica & Bovina & In vitro & $\begin{array}{l}\text { Moderada } \\
\text { atividade }\end{array}$ \\
\hline $\begin{array}{c}\text { Faccin et al., } \\
2016 \\
\end{array}$ & $\begin{array}{c}\text { Schinus terebinthifolius } \\
\text { (Anacardiaceae) }\end{array}$ & Aroeira branca & Folhas & Extrato hidroalcoólico & NR & Antisséptico & Bovina & In vivo & $\begin{array}{c}\text { Alta } \\
\text { atividade } \\
\end{array}$ \\
\hline $\begin{array}{c}\text { Tenório et al., } \\
2016\end{array}$ & $\begin{array}{c}\text { Abarema cochliacarpos } \\
\text { (Leguminosae) }\end{array}$ & Barbatimão & Casca & $\begin{array}{c}\text { Extratos } \\
\text { ciclohexânico, } \\
\text { acetônico e etanólico }\end{array}$ & $\begin{array}{c}\text { Alcaloides, } \\
\text { flavonoides, } \\
\text { saponinas e taninos, } \\
\text { terpenos e } \\
\text { esteroides }\end{array}$ & Antibacteriana & Canina & In vitro & $\begin{array}{c}\text { Alta } \\
\text { atividade }\end{array}$ \\
\hline $\begin{array}{l}\text { Almeida et al., } \\
2017\end{array}$ & $\begin{array}{c}\text { Stryphnodendron } \\
\text { adstringens } \\
\text { (Fabaceae) }\end{array}$ & Barbatimão & Entrecasca & $\begin{array}{c}\text { Extrato seco, } \\
\text { (maceração estática da } \\
\text { casca do caule em } \\
\text { etanol de cereais) }\end{array}$ & NR & Antibacteriana & Bovina & In vitro & $\begin{array}{c}\text { Alta } \\
\text { atividade }\end{array}$ \\
\hline $\begin{array}{l}\text { Dantas et al., } \\
2017\end{array}$ & $\begin{array}{c}\text { Morus nigra } \\
\text { (Moraceae) }\end{array}$ & Amoreira & Folhas & $\begin{array}{c}\text { Frações hexânica, } \\
\text { clorofórmica, acetato } \\
\text { de etila }\end{array}$ & $\begin{array}{c}\text { Flavonoides } \\
\text { isoquercetina e } \\
\text { kaempferol-3-O- } \\
\text { rhamnosídeo, } \\
\text { rutina, }\end{array}$ & Acaricida & Bovina & & $\begin{array}{c}\text { Alta } \\
\text { atividade } \\
\text { para fração } \\
\text { clorofórmic } \\
\text { a } \\
\end{array}$ \\
\hline \multirow{4}{*}{$\begin{array}{c}\text { Faria et al., } \\
2017 \mathrm{a}\end{array}$} & $\begin{array}{l}\text { Stryphnodendron } \\
\text { adstringens } \\
\text { (Fabaceae) }\end{array}$ & Barbatimão & Casca & Extrato hidroalcoólico & NR & \multirow{4}{*}{ Acaricida } & \multirow{4}{*}{ Suína } & \multirow{4}{*}{ In vitro } & \multirow{4}{*}{$\begin{array}{c}\text { Alta } \\
\text { atividade }\end{array}$} \\
\hline & $\begin{array}{c}\text { Pterodon emarginatus } \\
\text { Vogel } \\
\text { (Fabaceae) } \\
\end{array}$ & $\begin{array}{l}\text { Sucupira, } \\
\text { Faveiro }\end{array}$ & Frutos & Óleo-resina & NR & & & & \\
\hline & $\begin{array}{c}\text { Copaifera spp } \\
\text { (Caesalpiniaceae) }\end{array}$ & Copaiba & Comercial & Óleo-resina & NR & & & & \\
\hline & $\begin{array}{c}\text { Lafoensia pacari A } \\
\text { (Lythraceae) }\end{array}$ & Dedaleiro & Casca & $\begin{array}{l}\text { Extrato hidroalcoólico } \\
\qquad 80 \% \\
\end{array}$ & NR & & & & \\
\hline $\begin{array}{c}\text { Faria et al., } \\
2017 \mathrm{~b}\end{array}$ & $\begin{array}{c}\text { Copaifera spp } \\
\text { (Caesalpiniaceae) }\end{array}$ & Copaíba & NR & $\begin{array}{c}\text { Oleorresina, óleo } \\
\text { essencial }\end{array}$ & $\begin{array}{c}\beta \text {-Cariofileno, } \\
\alpha \text {-copaeno }\end{array}$ & Antibacteriana & Bovina & In vitro & $\begin{array}{c}\text { Alta } \\
\text { atividade } \\
\text { para } \\
\text { oleorresina }\end{array}$ \\
\hline $\begin{array}{l}\text { Ferreira et al., } \\
\qquad 2017\end{array}$ & $\begin{array}{c}\text { Syzygium aromaticum } \\
\text { (Myrtaceae) }\end{array}$ & Cravo & Flores & $\begin{array}{c}\text { Óleo essencial } \\
\text { Hidrolato } \\
\text { Eugenol }\end{array}$ & $\begin{array}{c}\text { Eugenol } \\
\text { Acetato de eugenol } \\
\text { Cariofileno } \\
\text { Humuleno }\end{array}$ & Acaricida & Bovina & In vitro & $\begin{array}{c}\text { Alta } \\
\text { atividade } \\
\text { eugenol e o } \\
\text { óleo } \\
\text { essencial }\end{array}$ \\
\hline $\begin{array}{l}\text { Fontenelle et } \\
\text { al., } 2017\end{array}$ & $\begin{array}{c}\text { Mangifera indica } \\
\text { (Anacardiaceae) }\end{array}$ & Manga & Folha & Óleo essencial & $\begin{array}{c}\beta-\text { Selineno, óxido } \\
\text { de cariofileno e }\end{array}$ & Antifúngica & Canina & In vitro & $\begin{array}{c}\text { Alta } \\
\text { atividade }\end{array}$ \\
\hline
\end{tabular}


Research, Society and Development, v. 10, n. 8, e46710817223, 2021

(CC BY 4.0) | ISSN 2525-3409 | DOI: http://dx.doi.org/10.33448/rsd-v10i8.17223

\begin{tabular}{|c|c|c|c|c|c|c|c|c|c|}
\hline & & & & & $\begin{array}{c}\text { humuleno II } \\
\text { epóxido }\end{array}$ & & & & \\
\hline \multirow{3}{*}{$\begin{array}{l}\text { Oliveira et al., } \\
2017\end{array}$} & $\begin{array}{c}\text { Turnera ulmifolia } \\
\text { (Turneraceae) }\end{array}$ & $\begin{array}{l}\text { Flor-de- } \\
\text { Guarujá }\end{array}$ & $\begin{array}{l}\text { Folhas e } \\
\text { Raízes }\end{array}$ & \multirow{3}{*}{$\begin{array}{l}\text { Hidroacetônico, } \\
\text { hidroalcoólico }\end{array}$} & $\begin{array}{c}\text { Cumarinas, flavona } \\
\text { fitoesteroides } \\
\text { saponinas, } \\
\text { flavonoides, } \\
\text { catequinas e } \\
\text { triterpenoides } \\
\end{array}$ & \multirow{3}{*}{ Anti-helmíntica } & \multirow{3}{*}{ Caprina } & \multirow{3}{*}{ In vitro } & \multirow{3}{*}{$\begin{array}{c}\text { Alta } \\
\text { atividade }\end{array}$} \\
\hline & $\begin{array}{c}\text { Parkia platycephala } \\
\text { (Mimosoidae) }\end{array}$ & Faveira & $\begin{array}{l}\text { Folhas e } \\
\text { Sementes }\end{array}$ & & $\begin{array}{c}\text { fenóis, flavonas e } \\
\text { fitoesteroides }\end{array}$ & & & & \\
\hline & $\begin{array}{c}\text { Dimorphandra gardneriana } \\
\text { (Leguminosae) }\end{array}$ & Faveira-d'anta & $\begin{array}{l}\text { Folhas e } \\
\text { Cascas }\end{array}$ & & $\begin{array}{c}\text { Fenóis, taninos } \\
\text { condensados, } \\
\text { flavonas, } \\
\text { flavanonas, } \\
\text { fitoesteroides e } \\
\text { saponinas } \\
\end{array}$ & & & & \\
\hline $\begin{array}{l}\text { Pereira et al., } \\
2017 \\
\end{array}$ & $\begin{array}{c}\text { Mimosa tenuiflora } \\
\text { (Fabaceae) }\end{array}$ & Jurema preta & Casca & Extrato etanólico & & Antibacteriana & Bubalina & In vitro & $\begin{array}{c}\text { Alta } \\
\text { atividade }\end{array}$ \\
\hline $\begin{array}{l}\text { Ribeiro et al., } \\
2017\end{array}$ & $\begin{array}{c}\text { Eucalyptus staigeriana } \\
\text { (Myrtaceae) }\end{array}$ & Eucalipto & NR & $\begin{array}{c}\text { Nanoemulsão do óleo } \\
\text { essencial }\end{array}$ & $\begin{array}{c}\text { Geranial } \\
\text { Geraniol } \\
\text { Geranil acetato } \\
\text { Limoneno } \\
\end{array}$ & Anti-helmíntica & Ovina & In vitro & $\begin{array}{l}\text { Moderada } \\
\text { atividade }\end{array}$ \\
\hline $\begin{array}{l}\text { Santos et al., } \\
2017 \\
\end{array}$ & $\begin{array}{c}\text { Digitaria insularis } \\
\text { (Poaceae) }\end{array}$ & $\begin{array}{c}\text { Capim- } \\
\text { amargoso }\end{array}$ & Folhas & Extrato hidroetanólico & NR & Anti-helmíntica & Caprina & In vitro & $\begin{array}{c}\text { Baixa } \\
\text { atividade }\end{array}$ \\
\hline $\begin{array}{l}\text { Silva et al., } \\
2017\end{array}$ & $\begin{array}{c}\text { Cratylia argentea } \\
\text { (Fabaceae) }\end{array}$ & Feijão bravo & $\begin{array}{c}\text { Vagens, } \\
\text { sementes e } \\
\text { folhas } \\
\end{array}$ & Extrato aquoso & NR & Anti-helmíntica & Ovina & $\begin{array}{l}\text { In vivo } \\
\text { In vitro }\end{array}$ & $\begin{array}{l}\text { Moderada } \\
\text { atividade }\end{array}$ \\
\hline \multirow{2}{*}{$\begin{array}{l}\text { Souza et al., } \\
2017\end{array}$} & $\begin{array}{c}\text { Aloysia triphylla } \\
\text { (Verbenaceae) }\end{array}$ & Lúcia-lima & Folhas & Óleo essencial & $\begin{array}{c}\alpha \text {-Citral, E-carveol, } \\
\text { limoneno }\end{array}$ & \multirow{2}{*}{ Antibacteriana } & \multirow{2}{*}{ Peixes } & \multirow{2}{*}{ In vitro } & \multirow{2}{*}{$\begin{array}{c}\text { Alta } \\
\text { atividade }\end{array}$} \\
\hline & $\begin{array}{c}\text { Lippia alba } \\
\text { (Verbenaceae) }\end{array}$ & Erva Cidreira & Folhas & Óleo essencial & Linalol & & & & \\
\hline $\begin{array}{l}\text { Vieira et al., } \\
2017\end{array}$ & $\begin{array}{c}\text { Manilkara rufula } \\
\text { (Sapotaceae) }\end{array}$ & Maçaranduba & Folhas & Extrato Acetona & $\begin{array}{c}\text { Flavonoides e } \\
\text { taninos } \\
\text { condensados nas } \\
\text { frações } \\
\end{array}$ & Anti-tricomonas & Bovina & In vitro & $\begin{array}{c}\text { Alta } \\
\text { atividade }\end{array}$ \\
\hline $\begin{array}{l}\text { Corral et al., } \\
2018 \\
\end{array}$ & $\begin{array}{c}\text { Piper aduncum } \\
\text { (Piperaceae) }\end{array}$ & Aperta-ruão & Folhas & Óleo essencial & $\begin{array}{c}\text { Dillapiol, trans- } \\
\text { cariofileno }\end{array}$ & Anti-helmíntica & Peixe & In vivo & $\begin{array}{c}\text { Alta } \\
\text { atividade }\end{array}$ \\
\hline $\begin{array}{c}\text { Ferreira et al., } \\
2018 \\
\end{array}$ & $\begin{array}{c}\text { Citrus aurantifolia } \\
\text { (Rutaceae) }\end{array}$ & Lima & Fruta & Óleo essencial & Limoneno & Anti-helmíntico & Ovina & In vitro & $\begin{array}{c}\text { Alta } \\
\text { atividade } \\
\end{array}$ \\
\hline $\begin{array}{c}\text { Leonêz et al., } \\
2018 \\
\end{array}$ & $\begin{array}{l}\text { Spondias mombin } \\
\text { (Anacardiaceae) }\end{array}$ & Cajazeira & Folha & $\begin{array}{c}\text { Extrato } \\
\text { (decocção) } \\
\end{array}$ & NR & Antibacteriana & Caprina & In vitro & $\begin{array}{l}\text { Moderada } \\
\text { atividade } \\
\end{array}$ \\
\hline $\begin{array}{l}\text { Nader et al., } \\
2018\end{array}$ & $\begin{array}{l}\text { Croton urucurana } \\
\text { (Euphorbiaceae) }\end{array}$ & $\begin{array}{l}\text { Sangue de } \\
\text { dragão }\end{array}$ & $\begin{array}{c}\text { Casca e } \\
\text { entrecasca }\end{array}$ & $\begin{array}{c}\text { Extrato hexânico } \\
\text { Fração acetato e sua } \\
\text { subfração, e } \alpha \text {-Costol }\end{array}$ & NR & Antibiofilme & Bovina & In vitro & $\begin{array}{l}\text { Moderada } \\
\text { atividade }\end{array}$ \\
\hline \multirow{3}{*}{$\begin{array}{l}\text { Silva et al., } \\
2018\end{array}$} & $\begin{array}{c}\text { Cassia fistula } \\
\text { (Fabaceae) }\end{array}$ & $\begin{array}{l}\text { Cassia- } \\
\text { imperial } \\
\end{array}$ & Folhas & Frações proteicas & NR & \multirow{3}{*}{ Anti-helmíntica } & \multirow{3}{*}{ Caprina } & \multirow{3}{*}{ In vitro } & \multirow{3}{*}{$\begin{array}{c}\text { Alta } \\
\text { atividade } \\
\text { Cassia } \\
\text { imperial }\end{array}$} \\
\hline & $\begin{array}{c}\text { Combretum leprosum } \\
\text { (Combretaceae) }\end{array}$ & Mofumbo & Folhas & Frações proteicas & NR & & & & \\
\hline & $\begin{array}{c}\text { Lippia alba } \\
\text { (Verbenaceae) }\end{array}$ & Erva Cidreira & Folhas & Óleo essencial & Linalol & & & & \\
\hline \multirow{2}{*}{$\begin{array}{l}\text { Souza et al., } \\
2018\end{array}$} & $\begin{array}{c}\text { Cymbopogum flexuosus } \\
\text { (Poaceae) }\end{array}$ & Capim-limão & Folhas & Óleo essencial & $\begin{array}{c}\alpha \text {-citral e } \\
\beta \text {-citral }\end{array}$ & \multirow{2}{*}{ Antibacteriana } & \multirow{2}{*}{ Peixe } & \multirow{2}{*}{ In vitro } & \multirow{2}{*}{$\begin{array}{l}\text { Moderada } \\
\text { atividade }\end{array}$} \\
\hline & $\begin{array}{c}\text { Ocimum basilicum } \\
\text { (Lamiaceae) }\end{array}$ & Manjericão & Folhas & Óleo essencial & $\begin{array}{l}\text { Linalol e } \\
\text { eucaliptol }\end{array}$ & & & & \\
\hline \multirow{2}{*}{$\begin{array}{l}\text { Alves et al., } \\
2018\end{array}$} & $\begin{array}{c}\text { Plectranthus grandis } \\
\text { (Lamiaceae) }\end{array}$ & Boldo-grande & Folhas & \multirow{2}{*}{$\begin{array}{l}\text { Óleo essencial } \\
\text { Extrato etanólico }\end{array}$} & \multirow{2}{*}{$\begin{array}{l}\text { Sesquiterpenos } \beta \text { - } \\
\text { cariofileno, a- } \\
\text { copaeno, } \\
\text { Germacreno, } \beta \text { - }\end{array}$} & \multirow{2}{*}{ Antifúngica } & \multirow{2}{*}{$\begin{array}{c}\text { Pequeno } \\
\text { s } \\
\text { carnivos }\end{array}$} & \multirow{2}{*}{ In vitro } & \multirow{2}{*}{$\begin{array}{c}\text { Alta } \\
\text { atividade }\end{array}$} \\
\hline & $\begin{array}{c}\text { Plectranthus ornatus } \\
\text { (Lamiaceae) }\end{array}$ & Boldo chinês & Folhas & & & & & & \\
\hline
\end{tabular}


Research, Society and Development, v. 10, n. 8, e46710817223, 2021

(CC BY 4.0) | ISSN 2525-3409 | DOI: http://dx.doi.org/10.33448/rsd-v10i8.17223

\begin{tabular}{|c|c|c|c|c|c|c|c|c|c|}
\hline & & & & & $\begin{array}{c}\text { cariofileno e óxido } \\
\text { de cariofileno }\end{array}$ & & & & \\
\hline $\begin{array}{c}\text { Vieira et al., } \\
2018 \mathrm{a} \\
\end{array}$ & $\begin{array}{c}\text { Hymenaea martiana } \\
\text { (Fabaceae) }\end{array}$ & Jatobá & Folha & Extrato etanólico bruto & NR & Antitumoral & Canina & In vitro & $\begin{array}{c}\text { Alta } \\
\text { atividade }\end{array}$ \\
\hline $\begin{array}{c}\text { Vieira et al., } \\
2018 \mathrm{~b}\end{array}$ & $\begin{array}{c}\text { Hymenaea martiana } \\
\text { (Fabaceae) }\end{array}$ & Jatobá & Folha & Extrato etanólico bruto & Flavonoides & $\begin{array}{c}\text { Antibacteriana/ } \\
\text { antisséptica }\end{array}$ & Bovina & $\begin{array}{l}\text { In vitro } \\
\text { In vivo }\end{array}$ & $\begin{array}{c}\text { Alta } \\
\text { atividade }\end{array}$ \\
\hline $\begin{array}{l}\text { Assunção et } \\
\text { al., } 2019\end{array}$ & $\begin{array}{c}\text { Azadirachta indica A. } \\
\text { (Meliaceae) }\end{array}$ & Neem & $\begin{array}{c}\text { Resíduo da } \\
\text { semente do } \\
\text { Neem } \\
\end{array}$ & $\begin{array}{l}\text { Utilização do pó da } \\
\text { semente para fabricar } \\
\text { ração de frango }\end{array}$ & NR & Antibacteriana & Aves & In vivo & $\begin{array}{r}\text { Nenhuma } \\
\text { atividade }\end{array}$ \\
\hline \multirow{3}{*}{$\begin{array}{c}\text { Castro et al., } \\
\text { 2019a }\end{array}$} & $\begin{array}{c}\text { Croton conduplicatus } \\
\text { (Euphorbiaceae) }\end{array}$ & Quebra-faca & Folhas & \multirow{3}{*}{ Óleos voláteis } & \multirow{3}{*}{$\begin{array}{l}\text { Eucaliptol, } p \text { - } \\
\text { cimeno, metil } \\
\text { chavicol }\end{array}$} & \multirow{3}{*}{ Acaricida } & \multirow{3}{*}{ Bovina } & \multirow{3}{*}{ In vitro } & \multirow{3}{*}{$\begin{array}{c}\text { Alta } \\
\text { atividade }\end{array}$} \\
\hline & $\begin{array}{c}\text { Croton pulegiodorus } \\
\text { (Euphorbiaceae) }\end{array}$ & Velame & Folhas & & & & & & \\
\hline & $\begin{array}{c}\text { Croton grewioides } \\
\text { (Euphorbiaceae) }\end{array}$ & $\begin{array}{l}\text { Canelinha-de- } \\
\text { cheiro }\end{array}$ & Folhas & & & & & & \\
\hline $\begin{array}{l}\text { Castro et al., } \\
\text { 2019b }\end{array}$ & $\begin{array}{c}\text { Eugenia uniflora } \\
\text { (Myrtaceae) }\end{array}$ & Pitangueira & Folhas & $\begin{array}{l}\text { Extratos aquoso e } \\
\text { hidroalcoólico }\end{array}$ & $\begin{array}{c}\text { Flavonoides, } \\
\text { saponinas, taninos e } \\
\text { triterpenos }\end{array}$ & Anti-helmíntica & Ovina & $\begin{array}{l}\text { In vitro } \mathrm{e} \\
\text { in vivo }\end{array}$ & $\begin{array}{c}\text { Alta } \\
\text { atividade } \\
\text { para } \\
\text { E. uniflora }\end{array}$ \\
\hline $\begin{array}{c}\text { Kakimori et } \\
\text { al., } 2019\end{array}$ & $\begin{array}{c}\text { Musa paradisiaca } \\
\text { (Musaceae) }\end{array}$ & Bananeira & $\begin{array}{c}\text { Brácteas da } \\
\text { banana }\end{array}$ & $\begin{array}{c}\text { Extrato } \\
\text { hidroalcoólico } 10 \%\end{array}$ & $\begin{array}{c}\text { Polifenóis } \\
\text { flavonoides e } \\
\text { taninos }\end{array}$ & Anti-helmíntica & $\begin{array}{l}\text { Ovina } \\
\text { Bovina }\end{array}$ & In vitro & $\begin{array}{c}\text { Alta } \\
\text { atividade }\end{array}$ \\
\hline \multirow{2}{*}{$\begin{array}{l}\text { Maciel et al., } \\
2019\end{array}$} & $\begin{array}{c}\text { Asclepias curassavica } \\
\text { (Asclepiadaceae) }\end{array}$ & Oficial de Sala & $\begin{array}{l}\text { Flores, } \\
\text { folhas e } \\
\text { caules }\end{array}$ & \multirow{2}{*}{ Decocção } & \multirow{2}{*}{ NR } & \multirow{2}{*}{ Anti-helmíntica } & \multirow{2}{*}{ Bovina } & \multirow{2}{*}{ In vitro } & \multirow{2}{*}{$\begin{array}{c}\text { Alta } \\
\text { atividade }\end{array}$} \\
\hline & $\begin{array}{c}\text { Euphorbia pulcherrima } \\
\text { (Euphorbiaceae) }\end{array}$ & $\begin{array}{c}\text { Bico de } \\
\text { Papagaio }\end{array}$ & $\begin{array}{l}\text { Flores, } \\
\text { folhas e } \\
\text { caules }\end{array}$ & & & & & & \\
\hline $\begin{array}{c}\text { Medeiros et } \\
\text { al., } 2019\end{array}$ & $\begin{array}{c}\text { Eugenia pyriformis } \\
\text { (Myrtaceae) }\end{array}$ & Uvaia & Folhas & Óleo essencial & $\begin{array}{c}\text { Espatulenol e óxido } \\
\text { de cariofileno }\end{array}$ & Acaricida & Bovina & In vitro & $\begin{array}{c}\text { Alta } \\
\text { atividade }\end{array}$ \\
\hline $\begin{array}{l}\text { Pinto et al., } \\
2019\end{array}$ & $\begin{array}{c}\text { Rosmarinus officinalis } \\
\text { (Lamiaceae) }\end{array}$ & Alecrim & Folhas & Óleo essencial & $\begin{array}{c}\text { Eucaliptol, 2- } \\
\text { bornanona, } \\
\alpha \text {-pineno }\end{array}$ & Anti-helmíntica & $\begin{array}{l}\text { Ovina } \\
\text { Caprina }\end{array}$ & In vitro & $\begin{array}{c}\text { Alta } \\
\text { atividade }\end{array}$ \\
\hline $\begin{array}{l}\text { Rodrigues et } \\
\text { al., } 2019\end{array}$ & $\begin{array}{c}\text { Croton blanchetianus } \\
\text { (Euphorbiaceae) }\end{array}$ & $\begin{array}{l}\text { Marmeleiro } \\
\text { Preto }\end{array}$ & Folhas & Óleo essencial & $\begin{array}{c}\text { Cedrol } \\
\text { Eucaliptol } \\
\alpha \text {-pineno } \\
\end{array}$ & Acaricida & Bovina & In vitro & $\begin{array}{c}\text { Alta } \\
\text { atividade }\end{array}$ \\
\hline $\begin{array}{c}\text { Santos et al., } \\
2019 \\
\end{array}$ & $\begin{array}{c}\text { Allium sativum } \\
\text { (Alliaceae) }\end{array}$ & Alho & In natura & Extrato de alho & NR & Anti-helmíntico & Ovina & In vivo & NR \\
\hline $\begin{array}{l}\text { Silva et al., } \\
2019\end{array}$ & $\begin{array}{c}\text { Commiphora leptophloeos } \\
\text { (Burseraceae) }\end{array}$ & $\begin{array}{c}\text { Imburana de } \\
\text { cambão }\end{array}$ & $\begin{array}{c}\text { Folhas e } \\
\text { cascas }\end{array}$ & $\begin{array}{c}\text { Extrato } \\
\text { Etanólico bruto }\end{array}$ & $\begin{array}{c}C \text {-glicosil flavonas } \\
\text { isoorientina, } \\
\text { orientina, } \\
\text { isovitexina e } \\
\text { vitexina }\end{array}$ & $\begin{array}{c}\text { Antibacteriana/ } \\
\text { antibiofilme }\end{array}$ & $\begin{array}{l}\text { Bovina } \\
\text { Bualina } \\
\text { Caprina }\end{array}$ & In vitro & $\begin{array}{c}\text { Alta } \\
\text { atividade }\end{array}$ \\
\hline $\begin{array}{l}\text { Sperandio et } \\
\text { al., } 2019\end{array}$ & $\begin{array}{c}\text { Tagetes minuta } \\
\text { (Asteraceae) }\end{array}$ & Chinchilho & Parte aérea & Óleo essencial & $\begin{array}{c}\text { cis-tagetona, di- } \\
\text { hidrotagetona, } \\
\text { 1,3,6-octatrieno- } \\
\text { 3,7-dimetil-E, } \\
\text { trans-ocimenona e } \\
\text { cis-ocimenona }\end{array}$ & Antibacteriana & Bovina & In vitro & $\begin{array}{c}\text { Alta } \\
\text { atividade }\end{array}$ \\
\hline
\end{tabular}

Fonte: Autores. 


\section{Discussão}

A utilização de plantas medicinais no tratamento ou prevenção das enfermidades comuns na criação de animais é uma atividade antiga que vem de várias gerações, e que até hoje segue sendo utilizada pelas comunidades, principalmente da zona rural (Lima et al., 2012). As práticas e saberes populares são ainda muito utilizados por muitos criadores, proprietários e veterinários para prevenir e tratar doenças em rebanhos e animais de estimação (Mathias, 2007; Monteiro et al., 2012). Entretanto, muitas plantas são utilizadas sem nenhum cuidado de doses e informações sobre toxicidade da planta, o que nos leva a entender que o conhecimento popular não é suficiente para validar a segurança e eficácia de determinado produto natural. Para isso, a grande maioria dos artigos aqui reunidos, partindo do conhecimento popular, validaram a eficácia e segurança, e principalmente, as propriedades terapêuticas de mais de 60 espécies de plantas.

No Brasil, existe uma variedade de espécies da flora nativa. Estas vegetações possuem diferentes características e princípios ativos que ainda são desconhecidos e que podem ser aproveitadas em estudos científicos para o desenvolvimento de fármacos (Varanda, 2006). Contudo, apesar da rica biodiversidade, ainda são poucos os fármacos formulados a partir de produtos naturais de espécies nativas quando comparado com a imensidão dos nossos biomas (Martins et al., 2019). Dessa forma, diante da vastidão de produtos naturais com inúmeras atividades terapêuticas que já são utilizadas empiricamente, os pesquisadores devem continuar se aprofundando cada vez mais para validar as propriedades curativas das plantas medicinais e buscar novos produtos e princípios ativos com potencial terapêutico (Pournejati \& Karbalaei-Heidari, 2018).

O presente estudo partiu da necessidade de reunir informações sobre estudos do uso de fitoterápicos na Medicina Veterinária e ter uma visão geral do que vem sendo trabalhado nos últimos anos. Dessa forma, analisando os trabalhos realizados aqui no Brasil e reunidos nesse estudo, observa-se a diversidade de espécies vegetais que vem sendo pesquisadas quanto à avaliação da atividade biológica, que vai desde a anti-helmíntica a antitumoral (Vieira et al., 2018b), e que, segundo os pesquisadores, podem ser usadas como alternativas naturais na prática veterinária.

A predominância de artigos que abordam as atividade anti-helmíntica de uma ou mais plantas deve-se ao fato de que muitas são as pesquisas com produtos naturais voltados à área da produção animal. Pode-se perceber nesse estudo que nos últimos vinte anos, as pesquisas com plantas medicinais vêm crescendo entre as linhas que buscam alternativas para o controle de parasitoses em animais de produção, e os resultados dessas pesquisas têm sido bastante promissores (Sinott et al., 2012; Maciel et al., 2019; Pinto et al., 2019).

O impacto financeiro que os nematoides gastrintestinais têm causado nos animais de produção como caprinos, ovinos, bovinos, aves e peixes, tem contribuído com o aumento inadequado nas aplicações e doses anti-helmínticas, gerando dessa forma, nematoides resistentes à maioria dos antiparasitários disponíveis, além dos resíduos tóxicos em produtos de origem animal e contaminação ambiental (Lumaret et al., 2012; Santos et al., 2019). O Brasil, líder mundial em rebanhos comerciais, é conhecido como um dos primeiros países a publicar artigos sobre a resistência anti-helmíntica em pequenos ruminantes (Salgado \& Santos 2016). Muitos pesquisadores brasileiros vêm ao longo dos anos estudando alternativas que sejam mais eficazes que os antihelmínticos convencionais e o uso de plantas medicinais tem se destacado nessas pesquisas como possíveis alternativas a esses medicamentos (Molento et al., 2013). No presente estudo, 49 artigos científicos se dedicaram à pesquisa de partes de cerca de 50 plantas usadas na etnoveterinária (Tabela 1) que apresentaram propriedades anti-helmínticas em extratos vegetais, decoctos, óleos essenciais, entre outros, e se mostraram eficientes principalmente nos testes in vitro, necessitando na grande maioria de melhores avaliações in vivo. Das plantas investigadas quanto às propriedades antiparasitárias, a abóbora (Nogueira et al., 2006; Almeida et al., 2007; Fujimoto et al., 2012; Feitosa et al., 2013) e o melão de São Caetano (Almeida et al., 2007; Cordeiro et al., 2010; Brito-Junior et al., 2011; Pereira et al., 2016) foram as mais citadas entre os artigos.

Fujimoto et al. (2012) avaliaram a eficácia de sementes de abóbora e mamão no controle de parasitos de peixes da espécie Astyanax cf. zonatus, e provaram que peixes alimentados com as sementes de abóbora tiveram redução no número de 
parasitas e concluíram, dessa forma, que essas sementes podem ser utilizadas como controle alternativo de nematoides intestinais do lambari. Feitosa et al. (2013) também avaliaram o efeito antiparasitário das sementes de abóbora em avestruzes e também comprovaram a eficácia das sementes no controle de helmintos gastrointestinais em aves. As sementes de abóbora também mostraram seu potencial anti-helmíntico nas espécies caprinas no estudo de Almeida et al. (2007), já na pesquisa realizada por Nogueira et al. (2006) a semente de abóbora não teve eficácia contra os nematoides caprinos testados.

Brito-Junior et al. (2011) estudaram os efeitos in vivo e in vitro do extrato etanólico das folhas do melão de São Caetano, e segundo os pesquisadores houve redução no número de ovos por grama de fezes de helmintos gastrointestinais em caprinos infectados, mostrando-se uma alternativa no controle desses parasitas.

Os gastos com anti-helmínticos aliados à busca por produtos saudáveis por parte do consumidor, tem aberto o leque para a pesquisa de medicamentos que sejam mais eficientes e seguros no controle dos parasitas gastrointestinais, e os pesquisadores têm apostado nos efeitos antiparasitários das plantas (Olivo et al., 2008; Nery et al., 2009; Grisi et al., 2014; Santos et al., 2019). Nesse sentido, os produtos naturais, sobretudo as plantas medicinais, são vistas como importantes alternativas no controle de nematoides intestinais pelo fato de que são mais seguras para os animais e acarretam menos impacto ambiental (Santos et al., 2019).

Por muitos anos os antimicrobianos se mostraram como fonte mais eficaz para o tratamento de doenças bacterianas. Contudo, o uso inadequado desses fármacos levou ao surgimento de bactérias potencialmente resistentes aos seus princípios ativos. Nesse ponto, os pesquisadores têm visto nas plantas medicinais uma opção na busca de novos compostos eficazes e seguros para tratar doenças infecciosas em animais (Leonez et al., 2018). Muitas plantas utilizadas na medicina etnoveterinária já tiveram sua ação antimicrobiana comprovada in vitro e in vivo em vários estudos frente a diversos microrganismos. Esse estudo destaca 56 pesquisas sobre a atividade antimicrobiana: antibacteriana (33), antifúngica (17) e antisséptica (6) de mais de 40 espécies de plantas (Tabela 1). O jatobá (Sá et al., 2011; Silva et al., 2014; Fernandes et al., 2015; Peixoto et al., 2015; Peixoto et al., 2016; Vieira et al., 2018a), foi a planta mais citada quanto à investigação de sua atividade antibacteriana e antisséptica.

Outra atividade antimicrobiana encontrada nos estudos aqui reunidos é a atividade antifúngica. A dermatofitose é uma zoonose de relativa importância principalmente em carnívoros domésticos. O combate é feito com o uso de fungicidas, contudo, são poucas a opções de fungicidas no mercado farmacêutico para pets. Além disso, são necessárias altas concentrações para que os produtos apresentem o efeito desejado, o que traz riscos para a saúde do animal, necessitando de outras alternativas de fungicidas disponíveis (Frias \& Kozusny-Andreani, 2009; Soares et al., 2015; Alves et al., 2018). Nesse sentido, muitos pesquisadores vêm trabalhando na tentativa de resolver esses problemas. Alguns estudos já comprovaram as propriedades antifúngicas de plantas medicinais. É o caso de Alves et al. (2018), que avaliaram a ação antifúngica de óleos essenciais e extratos de Plectranthus grandis e Plectranthus ornatos contra Trichophyton rubrum e Microsporum canis, fungos dermatófitos. Todas as plantas testadas apresentaram resultados significativos nos testes de concentração inibitória mínima, que variou de 0,078 $\mathrm{mg} / \mathrm{mL}$ a $0,31 \mathrm{mg} / \mathrm{mL}$ para todas as cepas testadas, indicando seus potenciais usos como antifúngicos na medicina veterinária. Dos 114 estudos reunidos, 6 estudaram a ação antisséptica de uma ou mais plantas (Tabela 1).

São inúmeros os estudos publicados sobre a atividade antimicrobiana de plantas medicinais nos últimos 20 anos guiados pelo uso popular. Entretanto, diante do crescente surgimento de micro-organismos resistentes aos medicamentos convencionais, tem-se incentivado ainda mais as pesquisas em busca de novas alternativas de antimicrobianos, sobretudo na medicina veterinária (Schimitt et al., 2003; Fontonelle et al., 2008; Pereira et al., 2009b; Silva et al., 2010; Pozzo et al., 2012; Mota et al., 2013; Moreira et al., 2014; Peixoto et al., 2015; Tenório et al., 2016; Fontenelle, 2017; Alves, 2018; Assunção et al., 2019; Silva et al., 2019).

Outro grande problema que tem chamado a atenção de inúmeros pesquisadores na medicina veterinária são os prejuízos causados pela infestação de carrapatos Rhipicephalus (Boopilus) microplus na bovinocultura brasileira. Estes prejuízos devem- 
se principalmente ao hematofagismo do parasita, comprometendo os produtos de origem animal pela inoculação de toxinas no hospedeiro e da transmissão de doenças (Pivoto et al., 2010). Na tentativa de combater esse problema, existem no mercado inúmeros acaricidas das mais variadas marcas, contudo, a resistência ao princípio ativo desses medicamentos levou ao aumento nas doses e frequência das aplicações, o que tem resultado em contaminação do meio ambiente e resíduos na carne e no leite, além de parasitas multirresistentes (Leal et al., 2003; Dantas et al., 2016). Nesse sentido, a necessidade de medicamentos mais seguros para o homem, animais e meio ambiente impulsionou várias pesquisas com o objetivo de encontrar novas alternativas para os acaricidas convencionais, entre as quais, extratos e óleos essenciais de plantas têm se revelado como eficazes acaricidas naturais (Martins, 2006; Andrade et al., 2013; Cruz et al., 2013; Rodrigues et al., 2019).

Foram identificados 24 artigos que estudaram ação acaricida de uma ou mais espécies medicinais, sendo a citronela (Olivio et al., 2008; Santos et al., 2012a; Melo et al., 2014) e o neen (Broglio-Michelettie et al., 2009; Giglioti et al., 2011) as plantas com maior número de artigos quanto às suas propriedades carrapaticidas. Conforme as pesquisas, o óleo essencial da citronela e extratos etanólico e hexânico do neem apresentaram resultados significativos no controle do carrapato bovino, mostrando serem alternativas aos acaricidas normalmente utilizados no combate desses parasitas (Olivio et al., 2008; BroglioMichelettie et al., 2009; Giglioti et al., 2011; Santos et al., 2012b; Melo et al., 2014). O neem também foi citado como possível alternativa no controle dos ectoparasitas caninos, contudo, segundo Andrade et al. (2013) o extrato etanólico bruto de Azadirachta indica testada in vitro contra carrapatos de cães mostrou-se com baixa eficácia (Tabela 1).

Outros estudos que se apresentaram em menor número, mas que têm mostrado resultados significativos, são as pesquisas das propriedades antiviral (Barros et al., 2012; Kaziyama et al., 2012), antitumoral (Vieira et al., 2018b) e cicatrizante (Oliveira et al., 2010) de plantas medicinais.

As plantas medicinais são fontes promissoras para a obtenção de novos produtos, uma vez que existe cerca de meio milhão de plantas em todo o mundo, e a maioria delas ainda não foi investigada quanto ao seu potencial terapêutico, podendo ser decisivas no tratamento de enfermidades em animais, sendo objeto de estudos atuais e futuros (Schmidt et al., 2003; Newman \& Cragg, 2012; Singh, 2015; Batista et al., 2016; Adnan et al., 2019). Outro grande problema é que apesar da quantidade de artigos aqui reunidos sobre o potencial terapêutico de uma ou mais plantas, ainda é muito pouco comparado à vastidão de plantas que vêm sendo pesquisadas quanto às suas propriedades terapêuticas na medicina veterinária.

\section{Conclusão}

Em conclusão, os estudos aqui analisados relataram o uso de várias plantas com atividades biológicas para diversas enfermidades em animais. Contudo, apesar da representatividade de estudos relatados nessa revisão de literatura ser pequena, quando comparado a inúmeros artigos publicados nos últimos anos, o estudo nos traz informações valiosas de possíveis alternativas medicamentosas naturais a serem utilizadas na medicina veterinária. Sendo assim, o uso de produtos naturais na medicina veterinária deve ser incentivado através de estudos científicos que comprovem a sua eficácia terapêutica e incluí-los nos protocolos da clínica veterinária. É importante também encorajar os pesquisadores a estudar a composição química dessas plantas, de forma a se fazer uma correlação entre as moléculas encontradas com as atividades biológicas apresentadas pelas espécies.

\section{Agradecimentos}

Os autores agradecem à Fundação de Amparo à Ciência e Tecnologia do Estado de Pernambuco (FACEPE) pela bolsa de doutorado concedida à aluna Isamara Ferreira da Silva (Processo IBPG-0133-5.05/19). 


\section{Referências}

Adnan, M., Uddin Chy, M. N., Kamal, A. T. M. M., Barlow, J. W., Faruque, M. O., Yang, X., \& Uddin, S. B. (2019). Evaluation of anti-nociceptive and antiinflammatory activities of the methanol extract of Holigarna caustica (Dennst.) Okenleaves. Journal Ethnopharmacology, 236, 401-441. 10.1016/j.jep.2019.01.025

Agnolin, C. A., Olivo, C. J., \& Parra, C. L. C. (2014). Efeito do óleo de capim limão (Cymbopogon flexuosus Stapf) no controle do carrapato dos bovinos. Revista Brasileira de Plantas Medicinais, 16 (1), 77-82. 10.1590/S1516-05722014000100011

Ahmad, T. B., Rudd, D., Smith, J., Kotiw, M., Mouatt, P., Seymour, L.M., Li L., \& Benkendorff, K. (2017). Anti-inflammatory activity and structure-activity relationships of brominated indoles from a marine mollusc. Marine Drugs, 15 (133), 1-19. 10.3390/md15050133

Almeida, W. V. F., Silva, M. L. C. R., Farias, E. B., Athayde, A. C. R., \& Silva, W. W. (2007). Avaliação de plantas medicinais em caprinos da região do semiárido paraibano naturalmente infectados por nematóides gastrintestinais. Caatinga, 20 (3), 1-7. http://www.redalyc.org/articulo.oa?id=237117565001

Almeida, G. F. D., Thamsborg, S. M., Madeira, A. M. B. N., Ferreira, J. F. S., Magalhaes, P. M., Demattê Filho, L. C., Horsted k., \& Hermansen, J. E. (2014). The effects of combining Artemisia annua and Curcuma longa ethanolic extracts in broilers challengedwith infective oocysts of Eimeria acervulina and E. maxima. Parasitology, 141, 347-355. 10.1017/S0031182013001443

Almeida, A. C., Morão, R. P., Martins, E. R., Fonseca, F. S. A., Souza, C. N., Prates, J. P. B., Oliveira, F. D., \& Silva, L. M. V. (2016). Atividade antisséptica do óleo essencial de Lippia origanoides Cham. (Alecrim-pimenta) na presença de leite bovino. Pesquisa Veterinária Brasileira, 36 (9), 905-911. 10.1590/S0100736 X2016000900018

Almeida, A. C., Andrade, V. A., Fonseca, F. S. A., Santo, R. L., Golen, K. G. F., Macedo, A. A., Martins, E. R., \& Macedo, N. A. (2017). Acute and chronic toxicity and antimicrobial activity of the extract of Stryphnodendron adstringens (Mart.) Coville. Pesquisa Veterinária Brasileira, 37 (8), 840-846. $10.1590 / \mathrm{s} 0100-736 \times 2017000800010$.

Alves, F. A. R., Morais, S. M., Sobrinho, A. C. N., Silva, I. N. G., Martins, C. G., Silva, A. A. S., \& Fontenelle, R. O. S. (2018). Chemical composition, antioxidant and antifungal activities of essential oils and extracts from Plectranthus spp. against dermatophytes fungi. Revista Brasileira de Saúde e Produção Animal, 19 (1), 105-115. 10.1590/S1519-99402018000100010

Andrade, A. W., Soares, G. W. N., Bezerra, T. I. C., Souza, M. G., Silva, F. M. F., Almeida, J. R. G. S., \& Horta, M. C. (2013). Avaliação da eficácia de extratos vegetais no controle do Rhipicephalus sanguineus provenientes do município de Juazeiro, Bahia. Evolvere Scientia, 2 (1),1-8. http://scientia.univasf.edu.br/vol2/paper01-pp1-8.pdf

Assis, L. M., Bevilaqua, C. M. L., Morais, S. M., Vieira, L. S., Costa, C. T. C., \& Souza, J. A. L. (2003). Ovicidal and larvicidal activity in vitro of Spigelia anthelmia Linn. extracts on Haemonchus contortus. Veterinary Parasitology, 117, 43-49. 10.1016/j.vetpar.2003.07.02

Assunção, P. S., Mello, H. H. C., Mascarenhas, A. G., Andrade, M. A., Teixeira, K. A., Oliveira, H., \& Carvalho, D. P. (2019). Use of neem (Azadirachta indica) as a substitute for antimicrobial drugs in broiler chickens' feed. Ciência Animal Brasileira, 20,1-9. 10.1590/1089-6891v20e-52588

Barbosa, C. S., Borges, L. M., Nicácio, J., Alves, R. D., Miguita, C. H., Violante, I. M., Hamerski, L., Garcez, W. S., \& Garcez, F. R. (2013). In vitro activities of plant extracts from the Brazilian Cerrado and Pantanal against Rhipicephalus (Boophilus) microplus (Acari: Ixodidae). Experimental and Applied Acarology, 60, 431-43. 10.1007/s10493-013-9656-Z

Barros, A. V., Araújo, L. M., Oliveira, F. F., Conceição, A. O., Simoni, I. C., Fernandes, M. J. B., \& Arns, C. W. (2012). Avaliação in vitro do potencial antiviral de Guettarda angelica contra herpes vírus animais. Acta Scientiae Veterinariae, 40 (4),1-7. http://www.ufrgs.br/actavet/40-4/PUB\%201068.pdf

Batista, L. S. O., Cid, Y. P., Almeida, A. P., Prudêncio, E. R., Riger, C. J., Souza, M. A. A., Coumendouro, K., \& Chaves, D. S. A. (2016). In vitro efficacy of essential oils and extracts of Schinus molle L. against Ctenocephalides felis felis. Parasitology, 143, 627-638. 10.1017/S0031182016000081

Bezerra, D. A. C., Andréia, V. P., Lôbo, K. M. S., Rodrigues, O. G., Athayde, A. C. R., Mota, R. A., Medeiros, E. S., \& Rodrigues, S. C. (2009). Atividade biológica da jurema-preta (Mimosa tenuiflora (Wild) Poir.) sobre Staphylococcus aureus isolado de casos de mastite bovina. Revista Brasileira Farmacognosia, 19 (4), 814-817. 10.1590/S0102-695X2009000600002

Borges-do-Santos, R. R., L'opez, J. A., Santos, L. C., Zacharias, F., David, J. M., David, J. P., \& Lima, M. F. W. (2012). Biological effect of leaf aqueous extract of Caesalpinia pyramidalis in goats naturally infected with gastrointestinal Nematodes. Evidence-Based Complementary Alternative Medicine, 2012, 1-6. $10.1155 / 2012 / 510391$

Brandão, M. G. L., Cosenza, G. P., Moreira, R. A., \& Monte-mor, R. L. M. (2006). Medicinal plants and other botanical products from the Brazilian Official Pharmacopocia. Revista Brasileira de Farmacognosia, 16 (3), 408-420. 10.1590/S0102-695X2006000300020

Brito-Junior, L., Silva, M. C. R., Lima, L. H., Athayde, A. C. R., Silva, W. W., \& Rodrigues, O. G. (2011). Estudo comparativo da ação anti-helmíntica da batata de purga (Operculina hamiltonii) e do melão de são caetano (Mormodica charantia) em caprinos (Capra hircus) naturalmente infectados. Ciência Agrotecnica, 35 (4), 797-802. 10.1590/S1413-70542011000400020

Brito, D. R. B., \& Fernandes, R. M. (2013). Ação anti-helmíntica da Morinda citrifolia (noni) sobre Heterakis gallinarum.Semina: Ciências Agrárias, 34 (4),1775-1782. 10.5433/1679-0359.2013v34n4p1775.

Broglio-Micheletti, S. M., Valente, E. C. N., Souza, L. A., Dias, A. S., \& Araujo, A. M. N. (2009). Extratos de plantas no controle de Rhipicephalus (Boophilus) microplus (Canestrini, 1887) (Acari: Ixodidae) em laboratório. Revista Brasileira de Parasitologia Veterinária, 18 94), 44-48. 10.4322/rbpv.01804008

Buzatti, A., Krawczak, F. S., Pivoto, F. L., Vogel, F. S. F., Botton, S. A., Zanetti, G. D., Manfron, M. P., \& Sangioni, L. A. (2011). Atividade acaricida in vitro de Glechon spathulata Benth. sobre teleóginas de Rhipicephalus (Boophilus) microplus. Ciência Rural, 41 (10), 1813-1817. 10.1590/S010384782011001000023 
Camurça-Vasconcelos, A. L. F., Bevilaqua, C. M. L., Morais, S. M., Maciel, M. V., Costa, C. T. C., Macedo, I. T. F., Oliveira, L. M. B., Braga, R. R., Silva, R. A., \& Vieira, L. S. (2007). Anthelmintic activity of Croton zehntneri and Lippia sidoides essential oils. Veterinary Parasitology, 148, 288-294. 10.1016/j.vetpar.2007.06.012

Castro, K. N. C., Chagas, A. C. S., Costa-Junior, L. M., Canuto, K. M., Brito, E. S., Rodrigues, T. H. S., \& Andrade, I. M. (2019a). Acaricidal potential of volatile oils from Croton species on Rhipicephalus microplus. Revista Brasileira Farmacognosia, 29, 811-815. 10.1016/j.bjp.2019.09.001

Castro, L. L. D., Sprenger, L. K., Madrid, I. M., Oliveira, F. C., Oliveira, P. A., Castro, L. M., Berne, M. E. A., \& Leite, F. P. L. (2019b). Efeito in vitro e in vivo de extratos de Eugenia uniflora em nematódeos gastrintestinais de ovinos. Ciência Animal Brasileira, 20,1-12. 10.1590/1089-6891v20e-49037

Cavalcante, G. S., Morais, S. M., André, W. P. P., Ribeiro, W. L. C., Rodrigues, A. L. M., Lira, F. C. M. L., Viana, J. M., \& Bevalaqua, C. L. (2016). Chemical composition and in vitro activity of Calotropis procera (Ait.) latex on Haemonchus contortus. Veterinary Parasitology, 226, 22-25. 10.1016/j.vetpar.2016.06.012

Chagas, A. C. S., Vieira, L. S., Freitas, A. R., Araujo, M. R. A., Araujo-Filha, J. A., Aragão, W. R., \& Navaro, A. M. C. (2008). Anthelmintic efficacy of neem (Azadirachta indica A. Juss) and the homeopathic product Fator Vermes1 in Morada Nova sheep. Veterinary Parasitology, 151, 68-73. 10.1016/j.vetpar.2007.10.003

Cordeiro, L. N., Athayde, A. C. R., Vilela, V. L. R., Costa, J. G. M., Silva, W. A., Araujo, M. M., \& Rodrigues, O. G. (2010). Efeito in vitro do extrato etanólico das folhas do melão-de-São-Caetano (Momordica charantia L.) sobre ovos e larvas de nematóides gastrintestinais de caprinos. Revista Brasileira de Plantas Medicinais, 12 (4), 421-426. 10.1590/S1516-05722010000400004

Corral, A. C. T., Queiroz, M. N., Andrade-Porto, S. M., Morey, G. A. M., Chaves, F. C. M., Fernandes, V. L. A., Ono, E. A., \& Affonso, E. G. (2018). Control of Hysterothylacium sp. (Nematoda: Anisakidae) in juvenile pirarucu (Arapaima gigas) by the oral application o essential oil of Piper aduncum. Aquaculture. 494, 37-44. 10.1016/j.aquaculture.2028.04.062

Costa, C. T. C., Bevilaqua, C. M. L., Morais, S. M., Oliveira, L. M. B., Camurça-Vasconcelos, A. L. F., Maciel, M. V., \& Lima, K. S. (2011). Ovicidal and larvicidal activity of Cocos nucifera L. extracts on Haemonchus contortus. Ciência Animal, 21(2), 87-95. http://www.uece.br/cienciaanimal/dmdo...

Cragg, G. M., \& Neman, D. J. (2013). Natural products: a continuing source of novel drug leads. Biochimica Biophysica Acta, 1830, 3670-3695. 10.1016/j.bbagen.2013.02.008

Cruz, E. M. O., Costa-Junior, L. M., Pinto, J. A. D., Santos, D. A., Araujo, S. A., Arrigoni-Blank, M. A., Bacci, L., Alves, P. B., Cavalcanti, S. C. H., \& Blank, A. F. (2013). Acaricidal activity of Lippia gracilis essential oil and its major constituents on the tick Rhipicephalus (Boophilus) microplus. Veterinary Parasitology, 195, 198-202. 10.1016/j.vetpar.2012.12.046

Dantas, A. C. S., Machado, D. M. R., ARAUJO, A. C., Oliveira-Junior, R. G., Lima-Saraiva, S. R. G., Ribeiro, L. A. A., Almeida, J. R. G. S., \& Horta, M. C. (2015). Acaricidal activity of extracts from the leaves and aerial parts of Neoglaziovia variegata (bromeliaceae) on the cattle tick rhipicephalus (boophilus) microplus. Research in Veterinary Science, 100,165-168. 10.1016/j.rvsc.2015.04.012

Dantas, A. C. S., Araujo, A. C., Pacheco, A. G. M., Branco, A., Sangione, L. A., Almeida, J. R. G. S., \& Horta, M. C. (2016). Acaricidal activity of Amburana cearenses on the cattle tick Rhipicephalus (Boophilus) microplus. Ciência Rural, 46 (3), 536-541. 10.1590/0103-8478cr20150334

Dantas, A. C. S., Freira, D. P., Souza, G. R., Almeida, J. R. G. S., Rolim, L. A., Castro, R. N., \& Horta, M. C. (2017). Acaricidal activity of leaves of Morus nigra against the cattle tick Rhipicephalus microplus. Arquivo Brasileiro de Medicina Veterinária e Zootecnia, 69 (3), 523-528. 10.1590/1678-4162-8994

Dar, R. A., Shahnawaz, M., \& Qazi, P. H. (2017). General overview of medicinal plants: A review. Journal Phytopharmacology, 6 (6), 349-351. 10.31254/phyto

Domingues, L. F., Giglioti, R., Feitosa, k. A., Fantatto, R. R., Rabelo, M. D., Oliveira, M. C. S., Bechara, G. H., Oliveira, G. P., Barioni Junior, W., \& Chagas, A. C. S. (2013). In vitro and in vivo evaluation of the activity of pineapple (Ananas comosus) on Haemonchus contortus in Santa Inês sheep. Veterinary Parasitology, 197, 263-270. 10.1016/j.vetpar.2013.04.031

Faccin, A., Schuch, L. F. D., Schiavon, D. B. A., Gonçalves, C. L., Mota, F. V., \& Lessa, L. F. (2016). Use of hydroalcoholic extract of Schinus terebinthifolius Raddi in pre and post-milking antisepsis of the teat in dairy cows. Ciência Animal Brasileira, 17 (1), 90-97. 10.1590/1089-6891v17i123998

Faria, A. M., Santos, A. S., Ferreira, L. L., Bastos, T. S. A., Louly, C. C. B., Matos, M. P. C., Conceição, E. C., \& Moura, V. M. B. D. (2017a). Acaricidal activity of ethanolic extracts of Stryphnodendron adstringens and Lafoensia pacariand oil resins from Copaifera sp. and Pterodon emarginatus against Sarcoptes scabieivar. suis. Pesquisa Veterinária Brasileira, 37 (12), 1411-1415. 10.1590/S0100-736X2017001200009

Faria, M. J. M., Braga, B. C. A. S., Paula, J. R., André, M. C. D. P. B., Vaz, B. G., Carvalho, T. C., Romão, W., Costa, H. B., \& Conceição, E. C. (2017b). Antimicrobial activity of Copaifera SPP. against bacteria isolated from milk of cows with mastitis. Ciência Animal Brasileira, 18,1-14. 10.1590/1089-6891v18e39068

Féboli, A., Laurentiz, A. C., Soares, S. C. S., Augusto, J. G., Anjos, L. A., Magalhaes, L. G., Filardi, R. S., \& Laurentiz, R. S. (2016). Ovicidal and larvicidal activity of extracts of Opuntia ficus-indica against gastrointestinal nematodes of naturally infected sheep. Veterinary Parasitology, 226, 65-68. 10.1016/j.vetpar.2016.06.030

Feitosa, T. F., Vilela, V. L. R., Athayde, A. C. R., Braga, F. R., Dantas, E. S., Vieira, V. D., \& Melo, L. R. B. (2013). Anthelmintic efficacy of pumpkin seed (Cucurbita pepo Linnaeus, 1753) on ostrich gastrointestinal nematodes in a semiarid region of Paraíba State, Brazil. Tropical Animal Health Production, 45,123127. 10.1007/s11250-012-0182-5

Fernandes, A. W. C., Aquino, S. A. M. C., Gouveia, G. V., Almeida, J. R. G. S. \& Costa, M. M. (2015). Atividade antimicrobiana in vitro de extratos de plantas do bioma Caatinga em isolados de Escherichia coli de suínos. Revista Brasileira Plantas Medicinal, 17 (4), 1097-1102. 10.1590/1983-084x/14_159

Ferreira, L. E., Castro, P. M. N., Chagas, A. C. S., França, S. C., \& Beleboni, R. O. (2013). In vitro anthelmintic activity of aqueous leaf extract of Annona muricata L. (Annonaceae) against Haemonchus contortus from sheep. Experimental Parasitology, 134, 327-332. 10.1016/j.exppara.2013.03.032 
Ferreira, L. E., Benincasa, B. I., Fachin, A. L., França, S. C., Contini, S. S. H. T., Chagas, A. C. S., \& Beleboni, R. O. (2016). Thymus vulgaris L. essential oil and its main component thymol: Anthelmintic effects against Haemonchus contortus from sheep. Veterinary Parasitology, 228, 70-76. 10.1016/j.vetpar.2016.08.011

Ferreira, F. M., Delmonte, C. C., Novato, T. L. P., Monteiro, C. M. O., Daemon, E., Vilela, F. M. P., \& Amaral, M. P. H. (2017). Acaricidal activity of essential oil of Syzygium aromaticum, hydrolate and eugenol formulated or free on larvae and engorged females of Rhipicephalus microplus. Medical Veterinary Entomology,32, 41-47. 10.1111 / mve. 12259

Ferreira, L. E., Benincasa, B. I., Fachin, A. L., Contini, S. H. T., França, S. C., Chagas, A. C. S., \& Beleboni, R. O. (2018). Essential oils of Citrus aurantifolia, Anthemis nobile and Lavandula officinalis: in vitro anthelmintic activities against Haemonchus contortus.Parasites \&Vectors, 11, 269. 10.1186/s13071-0182849-x

Fontenelle, R. O. S., Moraes, S. M., Brito, E. H. S., Brilhante, R. S. N. Cordeiro, R. A., Nascimento, N. R. F., Kerntopf, M. R., Sidrim, J. J. C., \& Rocha, M. F. G. (2008). Antifungal activity of essential oils of Croton species from the Brazilian Caatinga biome. Journal of Applied Microbiology, 104, 1383-90. 10.1111/ j.1365-2672.2007.03707.x

Fontenelle, R. O. S., Sobrinho, A. C. N., Soares, B. V., Aguiar, F. L. L., Brito, E. H. S., Cavalcante, C. S. P., Rocha, M. F. G., \& Morais, S. M. (2017). Effect of essential oils from Mangifera indica L. cultivars on the antifungal susceptibility of Candida spp. strains isolated from dogs. Revista. Brasileira Saúde e Produção Animal, 18 (2), 337-346. 10.1590/S1519-99402017000200012

Frias, D. F. R., \& Kozusny-Andreani, D. I. (2009). Avaliação in vitro da atividade antifúngica de extratos de plantas e óleo de eucalipto sobre Trichophyton mentagrophytes. Revista Brasileira de Plantas Medicinais, 11(12), 216-220. 10.1590/S1516-05722009000200017

Fujimoto, R. Y., Costa, H. C., \& Ramos, F. M. (2012). Controle alternativo de helmintos de Astyanaxcf. zonatus utilizando fitoterapia com sementes de abóbora (Cucurbita maxima) e mamão (Carica papaya). Pesquisa Veterinária Brasileira, 32 (1), 5-10. 10.1590/S0100-736X2012000100002

Giglioti, R., Forim, M. R., Oliveira, H. N., Chagas, A. C. S., Ferrezini, J., Brito, L. G., Falcoski, T. O. R. S., Albuquerque, L. G., \& Oliveira, M. C. S. (2011). In vitro acaricidal activity of neem (Azadirachta indica) seed extracts with known azadirachtin concentrations against Rhipicephalus microplus. Veterinary Parasitology, 181, 309-315. 10.1016/j.vetpar.2011.03.053

Gomes, D. C., Lima, H. G., Vaz, A. V., Santos, N. S., Santos, F. O., Dias, E. R., Botura, M. B., Branco, A., \& Batatinha, M. J. M. (2016). In vitro anthelmintic activity of the Zizyphus joazeiro bark against gastrointestinal nematodes of goats and its cytotoxicity on vero cells. Veterinary Parasitology, 226, 10-16. 10.1016 / j.vetpar.2016.06.004

Grisi, L., Leite, R. C., Martins, J. R. S., Barros, A. T. M., Andreotti, R., Cancado, P. H. D., Perez de Leon, A. A., Pereira, J. B. \& Villela, H. S. (2014). Reassessment of the potential economic impact of cattle parasites in Brazil. Revista Brasileira de Parasitologia Veterinária, 23 (2), 150-156. 10.1590/S198429612014042

Gregory, L., Yoshihara, E., Ribeiro, B. L. M., Silva, L. K. F., Marques, E. C., Meira, Jr E. B. S., Rossi, R. S., Sampaio, P. H., Louvandini, H., \& Hasegawa, M. Y. (2015). Dried, ground banana plant leaves (Musa spp.) for the control of Haemonchus contortus and Trichostrongylus colubriformis infections in sheep. Parasitology Research, 114, 4545-51. 10.1007 / s00436-015-4700-z

Hashimoto, G. S. O., Neto, F. M., Ruiz, M. L., Acchile, M., Chagas, E. C., Chaves, FF. C. M., \& Martins, M. L. (2016). Essential oils of Lippia sidoides and Mentha piperita against monogenean parasites and their influence on the hematology of Nile tilapia. Aquaculture, 450, 182-186. 10.1016/j.aquaculture.2015.07.029

Hemeg, H. a., Moussa, I. M., Ibrahim, S., Dawoud, T. M., Alhaji, J. H., Mubarak, A. S., Kabli, S. A., Alsubki, R. A., Tawfik, A. M., \& Marouf, S. A. (2020). Antimicrobial effect of different microbial population. Saudi Journal of Biological Sciences, 27 (12), 3221-3227. 10.1016/j.sjbs.2020.08.015

Hernández-Rivera, P. (2017). Ingesta de productos naturalesos macrobióticos: una llamada de atención a lasalud pública. Enfermeria Actual, 33, 1-12. 10.15517/revenf.v0i33.28381

Hocayen, P. A. S., \& Pimenta, D. S. (2013). Extrato de plantas medicinais como carrapaticida de Rhipicephalus (Boophilus) microplus. Revista Brasileira de Plantas Medicinais, 15, 627-631. 10.1590/S1516-05722013000500001

Kakimori, M. T. A., Debiage, R. R., Gonçalves, F. M. F., Silva, R. M. G., Yoshihara, E., \& Mello-Peixoto, E. C. T. (2019). Anthelmintic and antioxidant potential of banana bracts (Musa paradisiaca) extract in ruminants. Acta Veterinária Brasileira,13,18-23. 10.21708/avb.2019.13.1.7917

Katiki, L. M., Chaggas, A. C. S., Takahira, R. K., Juliani, H. R., Ferreira, J. F. S., \& Amarante, A. F. T. (2012). Evaluation of Cymbopogon schoenanthus essential oil in lambs experimentally infected with Haemonchus contortus. Veterinary Parasitology, 186,312-318. 10.1016/j.vetpar.2011.12.003

Kaziyama, V. M., Fernandes, M. J. B., \& Simoni, I. C. (2012). Atividade antiviral de extratos de plantas medicinais disponíveis comercialmente frente aos herpesvírus suíno e bovino. Revista Brasileira de Plantas Medicinais, 14(3), 522-528. 10.1590/S1516-05722012000300015

Khattak, N. S., Nouroz, F., Inayat, Ur R., \& Noreen, S. (2015). Ethno veterinary uses of medicinal plants of district Karak, Pakistan. Journal Ethnopharmacology, 171, 273-279. 10.1016/j.jep.2015.05.048

Lans, C. (2019). Do recent research studies validate the medicinal plants used in British Columbia, Canada for pet diseases and wild animals taken into temporary care? Journal of Ethnopharmacology, 236, 366-392. 10.1016/j.jep.2019.02.030

Leal, A. T. Freitas, D. R. J., \&Vaz, Jr I. S. (2003). Perspectives for control of bovine tick. Acta Scientiae Veterinariae, 31(1),1-11. http://hdl.handle.net/10183/19793

Leonez, C. F., Feijo, F. M. C., Alves, N. D., Santos, C. S., Rodrigues, G. S. O., Fernandes, F. C., \& Matos, T. M. (2018). Efficacy of the decoction of cashew leaf (Spondias mombin L.) as a natural antiseptic in dairy goat matrices. African Journal of Agricultural Research, 13 (13), 644-649. 10.5897/AJAR2017.12751 
Lima, M. C., Santana, A. F., \& Viegas, S. R. A. A. (2010). Ação antimicrobiana de plantas taníferas em bactérias anaeróbias isoladas da pododermatite ovina. PUBVET, 4 (22), 1-11. https://www.pubvet.com.br/uploads/20525715f8a839ce5d5d0eb53209a831.pdf

Lima, R. P., Palitot, K. M., Rego, M. A. E., Xavier, F. J. R., \& Souza, A. E. F. (2012). Emprego de plantas medicinais em animais de companhia e de produção da zona rural do município de juru-pb. BioFar. 8, 85-92. https://docplayer.com.br/20142481

Lumaret, J. P., Errouissi, F., Floate, K., Römbke, J., \& Wardhaugh, K. (2012). A review on the toxicity and non-target effects of macrocyclic lactones in terrestrial and aquatic environments. Current Pharmaceutical Biotechnology, 13, 1004-1060. 10.2174/138920112800399257

Macedo, I. T., Bevilaqua, C. M. L., Oliveira, L. M. B., Camurça-Vasconcelos, A. L. F., Moraes, S. M., Machado, L. K. A., \& Ribeiro, W. L. C. (2012). In vitro activity of Lantana camara, Alpinia zerumbet, Mentha villosa and Tagete sminuta decoctions on Haemonchus contortus eggs and larvae. Veterinary Parasitology, 190,504-509. 10.1016/j.vetpar.2012.07.001

Macedo, I. T. F., Oliveira, L. M. B., Camurça-Vasconcelos, A. L. F., Ribeiro, W. L. C., Santos, J. M. L., Morais, S. M., Paula, H. C. B., \& Bevilaqua, C. M. L. (2013). In vitro effects of Coriandrum sativum, Tagetes minuta, Alpinia zerumbet and Lantana câmara essential oils on Haemonchus contortus. Revista Brasileira de Parasitologia Veterinária, 22(4), 463-469. 10.1590/S1984-29612013000400004

Maciel, L. T. R., Pereira, F. B. S., Akisue, G., Silva-Coelho, F. A., \& Coelho, M. D. G. (2019). Anticoccidial and toxicological activity of Asclepias curassavica L. and Euphorbia pulcherrima Willd. ex Klotzsch decocts against Eimeria bovisoocysts. PUBVET, 13 (4), 1-8. 10.31533/pubvet.v13n4a308.1-8

Mathias, E. (2007). Ethnoveterinary medicine in the era of evidence-based medicine: Mumbo jumbo or a valuable resource? The Veterinary Journal, 173, 241242. $10.1016 /$ j.tvjl.2005.12.005

Martins, R. M. (2006). Estudioin vitro de la acción acaricida del aceite esencial de la gramínea Citronela de Java (Cymbopogon winterianus Jowitt) em la garrapata Boophilus microplus. Revista Brasileira de Plantas Medicinais, 8 (2), 71-78. https://www.semanticscholar.org/paper/

Martins, D. T. O., Rodrigues, E., Casu, L., Benítez, G., \& Leonti, M. (2019). The historical devenlopment of pharmacopeias and the inclusion of exotic herbal drugs with a focus on Europe and Brazil. Journal Ethnopharmacology, 240, 111891. 10.1016/j.jep.2019.111891

Medeiros, J. P., Bortollucci, W. C., Silva, E. S., Oliveira, H. L. M., Campo, C. F. A. A., Gonçalves, J. E., Piau Junior, R., \& Gazim, Z. C. (2019). Biocidal potential of Eugenia pyriformis essential oil in the control of Rhipicephalus (Boophilus) microplus in the free-living cycle. Pesquisa Veterinária Brasileira, 39 (11), 879-888. 10.1590/1678-5150-pvb-6434

Melo, V., Prata, M. C. A., Silva, M. R., Daemon, E., Silva, L. S., Guimarães, F. G., Mendonça, A. E., Folly, E., Vilela, F. M. P., Amaral, L. H., Cabral, L. M., \& Amaral, M. P. H. (2014). Acaricidal properties of the formulations based on essential oils from Cymbopogon winterianus and Syzygium aromaticum plants. Parasitology Research, 113, 4431-4437. 0.1007/s00436-014-4121-4

Mendonça-Lima, F., Santos, R. B., Santos, L. C., Zacharias, F., David, J. M., David, J. P., \& Lopez, J. A. (2016). Anthelmintic activity of Cratyliamollis leaves against gastrointestinal nematodes in goats. Revista. Brasileira de Saúde e Produção Animal, 17 (4), 753-762. 10.1590/s1519-99402016000400018

Mesquita, M. A., Silva Junior, J. B., Panassol, A. M., Oliveira, E. F., Vasconcelos, A. L. C. F., Paula, H. C. S., \& Bevilaqua, C. L. M. (2013). Anthelmintic activity of Eucalyptus staigeriana encapsulated oil on sheep gastrointestinal nematodes. Parasitology Research, 112,3161-3165. 10.1007/s00436-013-3492-2

Molento, M. B., Veríssimo, C. J., Amarante, A. T., van Wyk, J., Chagas, A. C. S., Araújo, J. V., \& Borges, F. A. (2013). Alternativas para o controle de nematoides gastrintestinais de pequenos ruminantes. Arquivo Instituto de Biologia,80 (2), 253-263. 10.1590/S1808-16572013000200018

Monteiro, M. V. B., Bevilaqua, C. M. L., Moraes, S. M., Machado, L. K. A., Camurça-Vasconcelos, A. L. F., Campello, C. C., Ribeiro, W. L. C., \& Mesquita, M. A. (2011). Anthelmintic activity of Jatropha curcas L. seeds on Haemonchus contortus. Veterinary Parasitology, 182, 259-263. 10.1016/j.vetpar.2011.04.010

Monteiro, M. V. B., Rodrigues, S. T., \& Camurça-Vasconcelos, A. L. F. (2012). Plantas medicinais utilizadas na medicina etnoveterinária praticada na ilha do Marajó. Embrapa Amazônia Oriental, 380, 1-33.

Morais-Costa, F., Bastos, G. A., Soares, A. C. M., Costa, E. G. L., Vasconcelos, V. O., Oliveira, N. J. F., Braga, F. C., Duarte, E. R., \& Lima, W. S. (2016). In vitro and in vivo action of Piptadenia viridiflora (Kunth) Benth against Haemonchus contortus in sheep. Veterinary Parasitology, 223, 43-49. 10.1016/j.vetpar.2016.04.002

Moreira, G. M. B., Matsumoto, L. S., Silva, R. M. G., Domingues, P. F., \& Mello-Peixoto, E. C. T. (2014). Atividade antibacteriana do extrato hidroalcoólico de Punica granatum Linn. sobre Staphylococcus spp. isolados de leite bovino. Pesquisa Veterinária Brasileira, 34 (7), 626-632. 10.1590/S0100736X2014000700003

Moroole, M. A., Materechera, S. A., Mbeng, W. O., \& Aremu, A. O. (2019). Medicinal plants used for contraception in South Africa: A review. Journal of Ethnopharmacology, 235, 19-27. 10.1016/j.jep.2019.02.002

Mota, F. V., Schuch, L. F. D., Goncalves, C. L., Faccin, A., Schiavon, D. B. A., Bohm, B. C., \& Lessa, L. F. (2013). Actividad antibacteriana de los extractos de Syzygium cumini (L.) Skeels (jambolán) frente a los microorganismos asociados a la mastitis bovina. Revista Cubana de Plantas Medicinales, 18 (3), 495 501.

Nader, T. T., Coppede, J. S., Amaral, L. A., Facchin, A. L., Pereira, A. M. S., \& Ferreira, L. M. (2010). Avaliação In Vitro da eficácia de extratos de plantas medicinais do Cerrado frente Staphylococcus Aureus isolado de diferentes fontes de propriedades leiteiras. Arquivo do Instituto de Biologia, 77 (3), $429: 433$.

Nader, T. T., Coppede, J. S., Taleb-Contini, S. H., Amaral, L. A., \& Pereira, A. M. S. (2018). Atividade antibiofilme de substâncias de Croton urucurana em Staphylococcus aureus isolado de mastite bovina. Pesquisa Veterinária Brasileira, 38 (9), 1713-1719. 10.1590/1678-5150-PVB-5034

Nascimento, E. M., Furlong, J., Pimenta, D. S., \& Prata, M. C. A. (2009). Efeito anti-helmíntico do hidrolato de Mentha villosa Huds. (Lamiaceae) em nematóides gastrintestinais de bovinos. Ciência Rural, 39 (3), 817-804. 10.1590/S0103-84782009005000017 
Nery, P. S., Duarte, E. R., \& Martins, E. R. (2009). Eficácia de plantas para o controle de nematóides gastrintestinais de pequenos ruminantes: revisão de estudos publicados. Revista Brasileira de Plantas Medicinais, 11 (3), 330-338. 10.1590/S1516-05722009000300016

Newman, D. J., \& Cragg, G. M. (2012). Natural Products as Sources of New Drugs over the 30 Years from 1981 to 2010. Journal of Natural Products, 75, 311335. $10.1021 / \mathrm{np} 200906 \mathrm{~s}$

Nogueira, D. M., Moreira, J. N., \& Carlos, J. F. (2006). Avaliação de plantas medicinais no controle de nematódeos gastrintestinais de caprinos criados em sistema de base agroecológica. Revista Cientifica de Produção Animal, 8, 35-40. https://www.embrapa.br/busca-de-publicacoes/

Oliveira, L. M. B., Bevilaqua, C. M. L., Costa, C. T. C., Macedo, I. T. F., Barros, R. S., Rodrigues, A. C. M., Camurca-Vasconcelos, A. L. F., Morais, S. M., Lima, Y. C., Vieira, L. S., \& Navarro, A. M. C. (2009). Anthelmintic activity of Cocos nucifera L. against sheep gastrointestinal nematodes. Veterinary Pasitology, 159, 55-59. 10.1016/j.vetpar.2008.10.018

Oliveira, A. F., Batista, J. S., Paiva, E. S., Farias, Y. J. M. D., Damasceno, C. A. R., Brito, P. D., Queiroz, S. A. C., Rodrigues, C. M. F., Freitas, C. I. A. (2010). Avaliação da atividade cicatrizante do jucá (Caesalpinia ferrea Mart. ex Tul. var. ferrea) em lesões cutâneas de caprinos. Revista Brasileira de Plantas Medicinais, 12 (3), 302-310. 10.1590/S1516-05722010000300007

Oliveira, L. M. B., Bevilaqua, C. M. L., Macedo, I. T. F., Moraes, S. M., Machado, L. K. A., Campello, C. C., \& Mesquita, M. A. (2011). Effects of Myracrodruon urundeuva extracts on egg hatching and larval exsheathment of Haemonchus contortus. Parasitology Research, 109, 893-898. 10.1007/s00436-011-2331-6

Oliveira, A. F., Costa Junior, L. M., Lima, A. S., Silva, C. R., Rieiro, M. N. S. Mesquita, J. W. C., Rocha, C. Q., Tangerina, M. M. P., \& Vilegas. (2017). Anthelmintic activity of plant extracts from Brazilian savanna. Veterinary Parasitology, 236, 121-127. 10.1016/j.vetpar.2017.02.005

Olivo, C. J., Carvalho, N. M., Silva, J. H. S., Vogel, F. F., Massariol, P., Agnolin, G. M. C., Morel, A. F., \& Viau, L. V. (2008). Óleo de citronela no controle do carrapato de bovinos. Ciência Rural. 38 (2), 406-410. 10.1590/S0103-84782008000200018

Peixoto, R. M., Araujo, R. M. P., Peixoto, L. J. S., Bomfim, S. A. G., Silva, T. M. G., Silva, T. M. S., Almeida, J. R. G. S., Mota, R. A., \& Costa, M. M. (2015). Treatment of goat mastitis experimentally induced by Staphylococcus aureus using a formulation containing Hymenaea martiana extract. Small Ruminante Research, 130, 229-235. 10.1016/j.smallrumres.2015.07.009

Peixoto, R. M., Silva, W. E., Almeida, J. R. G. S., Branco, A., \& Costa, M. M. (2016). Antibacterial potential of native plants from the Caatinga biome against Staphylococcus spp. isolates from small ruminants with mastitis. Revista Caatinga, 29 (3), 758-763. 10.1590/1983-21252016v29n328rc

Pereira, A. V., Lobo, K. M. S., Bezerra, D. A. C., Rodrigues, O. G., Athayde, A. C. R., Mota, R. A., Lima, E. Q., \& Medeiros, E. S. (2009a). Perfil de sensibilidade antimicrobiana in vitro de jurema-preta e neem sobre amostras de Staphylococcus sp. isoladas de mastite em búfalas. Arquivo do Instituto de Biologia, 76 (3), 341-346. http://www.biologico.sp.gov.br/uploads/docs/arq/v76_3/pereira.pdf

Pereira, A. V., Rodrigues, O. G., Lobo, K. M. S., Bezerra, D. A. C., Mota, R. A., Coutinho, L. C. A., Silva, L. B. G., \& Athayde, A. C. R. (2009b). Atividade anti-fúngica do neem e jurema-preta sobre cepas de Candida spp isolados de vacas com mastite subclínica no Estado de Pernambuco. Revista Brasileira de Farmacognosia, 19 (4), 818-822. 10.1590/S0102-695X2009000600003

Pereira, C. A. J., Oliveira, L. L. S., Coaglio, A. L., Santos, F. S. O., Cezar, R. S. M., Mendes, T., Oliveira, F. L. P., Conzensa, G., \& Walter, S. L. (2016). Antihelminthic activity of Momordica charantia L. against Fasciola hepatica eggs after twelve days of incubation in vitro. Veterinary Parasitology, 228, 160-166. 10.1016/j.vetpar.2016.08.025

Pereira, A. V., Gois, M. B., Ferraz, F. N., Pereira, J. V., Azevedo, S. S., Lima, E. Q., Rodrigues, O. G., Medeiros, E. S., Mota, R. A., \& Pereira, M. S. V. (2017). Miimosa tenuiflora extract reduces the number of Staphylococcus aureus with low toxicity in bubalus bubalis with mastitis. Buffalo Bulletin, 36, 21-26. http://ibic.lib.ku.ac.th/.../36-1.pdf

Pinto, N. B., Castro, L. M., Azamuja, R. H. M., Capella, G. A., Moura, M. Q., Terto, W. D., Freita, R. A., Jeske, S. T., Villela, M. M., Cleffi, M. B., \&Leite, F. P. L. (2019). Ovicidal and larvicidal potential of Rosmarinus officinalis to control gastrointestinal nematodes of sheep. Brazilian Journal of Veterinary Parasitology, 28 (4), 807-811. 10.1590/S1984-29612019060

Pivoto, F. L., Buzzati, A., KrawczakI, F. S., Camillo, J., SangioniI, L. A., Zanetti, G. D., Manfron, M. P., \& Vogel, F. S. F. 2010. Ação acaricida in vitro de Tropaeolum majus sob teleóginas de Rhipicephalus (Boophilus) microplus. Ciência Rural, 40 (10), 2141-2145.https://www.scielo.br/

Pournejati, R., \& Karbalaei-Heidari, H. R. (2018). Searching for New Bioactive Metabolites from Marine Bacteria in the Persian Gulf: Antibacterial, Cytotoxic and Anti-inflammatory Agents. International Journal of Biological Macromolecules, 4, 78-92. 10.1016/j.jep.2016.10.071

Pozzo, M. D., Loreta, S. E., Santurio, D. F., Alves, S. H., Rassatto, L., Vargas, A. C., Viegas, J., \& Costa, M. M. (2012). Antibacterial Activity of Essential Oil of Cinnamon and Trans-cinnamaldehyde against Staphylococcus spp. Isolated from Clinical Mastitis of Cattle and Goats. Acta Scientiae Veterinariae, 40 (4),15. http://www.ufrgs.br/actavet/40-4/PUB\%201080.pdf

Ribeiro, A. R. C., Andrade, F. D., Medeiros, M. C., Camboim, A. S., Pereira Junior, F. A., Athayde, A. C. R., Rodrigues, O. G. \& Silva, W. W. (2014). Estudo da atividade anti-helmíntica do extrato etanólico de Jatropha mollissima (Pohl) Baill. (Euphorbiaceae) sob Haemonchus contortus em ovinos no semiárido paraibano. Pesquisa Veterinária Brasileira,34 (11), 1051-1055. https://www.scielo.br/

Ribeiro, L. C., Camurça-Vasconcelos, A. L. F., Santos, J. M. L., Macedo, I. T. F., Ribeiro, J. C. Oliveira, E. F., Paula, H. C. B., \& Bevilaqua, C. M. L. (2017). The use of Eucalyptus staigeriana nanoemulsion for control of sheep haemonchosis. Pesquisa Veterinária Brasileira, 37 (3), 221-226. 10.1590/S0100736X2017000300004

Righi, A. A., Motta, L. B., Klafke, G. M., Pohl, P. C., Furlan, C. M., Santos, D. Y. A. C., Salatino, M. L. F., Negri, G., Labruna, M. B., \& Salatino, A. (2013). Chemical composition and efficacy of dichloromethane extract of Croton sphaerogynus Baill. (Euphorbiaceae) against the cattle tick Rhipicephalus microplus (Acari: Ixodidae). Veterinary Parasitology, 192, 292-295. 10.1016/j.vetpar.2012.11.005 
Rodrigues, O. G., Falcão, B. R. M., Barrosa, B. C., Pereira, A. V., \& Aquino, V. V. F. (2019). In vitro biological activity of the Croton blanchetianus (Baill) essential oil against Rhipicephalus (Boophilus) microplus (Acari: Ixodidae). Journal of Applied Biology Biotechnology, 7, (2), 55-58. https://www.bibliomed.org/?mno=250800

Sá, M. C. A., Peixoto, R. M., Krewer, C. C., Almeida, J. R. G. S., Vargas, A. C., \& Costa, M. M. (2011). Antimicrobial activity of Caatinga biome ethanolic plant extracts against gram negative and positive bacteria. Revista Brasileira de Ciências Veterinária, 18, 62-66. 10.4322/rbcv.2014.122

Salgado, J. A., \& Santos, C. P. (2016). Overview of anthelmintic resistance of gastrointestinal nematodes of small ruminants in Brazil. Brazilian Journal of Veterinary Parasitology, 25 (1), 3-17. 10.1590/S1984-29612016008

Santos, F. C. C., Vogel, F. S. F., \& Monteiro, S. G. (2012a). Efeito de diferentes concentrações de óleo e tintura de citronela sobre os parâmetros reprodutivos de teleóginas de Rhipicephalus (Boophilus) microplus. Semina: Ciências Agrárias, 33 (3), 1141-1148. 10.5433/1679-0359.2012v33n3p1141

Santos, F. C. C., Vogel, F. S. F., \& Monteiro, S. G. (2012b). Efeito do óleo essencial de manjericão (Ocimum basilicum L.) sobre o carrapato bovino Rhipicephalus (Boophilus) microplusem ensaios in vitro. Semina: Ciências Agrárias, 33 (3), 1133-1140. 10.5433/1679-0359.2012v33n3p1133

Santos, F. C. C., Vogel, F. S. F., Roll, V. F. B., \& Monteiro, S. G. (2013). In vitro effect of the association of citronella, santa maria herb (Chenopodium ambrosioides) and quassia tincture on cattle tick Rhipicephalus (Boophilus) microplus. Ciência Animal Brasileira, 14 (1), 113-119. 10.5216/cab.v14i1.19393

Santos, F. O., Lima, H. G., Santos, N. S. S., Serra, T. M., Uzeda, R. S., Reis, I. M. A., Botura, M. B., Branco, A., \& Batatinha, M. J. M. (2017). In vitro anthelmintic and cytotoxicity activities the Digitaria insularis (Poaceae). Veterinary Parasitology, 245, 48-54. 10.1016/ j.vetpar.2017.08.007

Santos, J. C., Oliveira, C. J., Severo, M., Custiel, F. A., Somavilla, M., \& Agnolin, C. A. (2019). Eficácia do alho como anti-helmíntico em ovinos. Boletim de Industria Animal, 76, 1-7. 10.17523/bia.2019.v76.e1446

Scapinelloj, J., Muller, L. G., Schindler, M. S. Z., Anzollin, G. S., Siebel, A. M., Boligon, A. A., Niero, R., Saraiva, T. E. S., Maus, M. P., Betti, A. H., Oliveira, J. V., Magro, J. D., \& Oliveira, D. (2019). Antinociceptive and anti-inflammatory activities of Philodendron bipinnatifidum Schott ex Endl (Araceae). Journal Ethnopharmacology, 236, 21-30. 10.1016/j.jep.2019.02.037

Schmitt, A. C., Almeida, A. B. P. F., Silveira, T. A., Iwakura, C. T., Mendes, K. F., \& Silva, M. C. (2003). Avaliação da atividade antimicrobiana in vitro da planta Bryophyllum pinnatum Kurz ("Folha-da-fortuna") colhida em Várzea Grande, Mato Grosso/Brazil. Acta Scientiae Veterinariae, 31 (1) 55-58. $10.22456 / 1679-9216.17035$

Schuch, L. F. D., Wiest, J. M., Coimbra, H. S., Prestes, L. S., Toni, L., \& Lenos, J. S. (2008a). Cinética da atividade antibacteriana in vitro de extratos naturais frente a microrganismos relacionados à mastite bovina. Ciência Animal Brasileira, 9, 161-169. https://revistas.ufg.br/vet/article/view/968

Schuch, L. F. D., Wiest, J. M., Garcia, E. N., Prestes, L. S., Schramm, R. C., Coimbra, H., \& Meireles, M. C. A. (2008b). Atividade antifúngica de extratos de plantas utilizados por agricultores familiares como antimicrobiano. Acta Scientiae Veterinariae, 36 (3), 267-271. 10.22456/1679-9216.17298

Silva, A. B., Silva, T., Franco, E. S., Rabelo, S. A., Lima, E. R., Mota, R. A., Camara, C. A. G., Ponntes-Filho, N. T., \& Lima-Filho, J. V. (2010). Antibacterial activity, chemical composition, and cytotoxicity of leaf's essential oil from brazilian pepper tree (schinus terebinthifolius, raddi). Brazilian Journal of Microbiology, 41,158-163. 10.1590/S1517-83822010000100023

Silva, A. B., César, V. S., Santos, A. C. G., \& Guerra, R. M. S. N. C. (2013). Avaliação do Efeito Dos Extratos de Cecropia hololeuca (Embaúba)e Musa sp. Variedade Fhia 18 (Bananeira) Sobre Culturas de Larvas de Nematódeos Gastrintestinais de Caprinos. Enciclopédia Biosfera, 9 (16), 411-422. https://conhecer.org.br/ojs/index.php/biosfera/article/view/3370

Silva, V. F., Franco, I., Damaceno, T. E. F., Almeida, J. R. G. S., \& Costa, M. M. (2014). Potencial antimicrobiano de extratos etanólicos de plantas frente a bacilos gram negativos isolados da mucosa cérvico-vaginal de ovelhas criadas na região de Petrolina-PE. Semina: Ciências Agrárias, 35, (2), 883-890. $10.5433 / 1679-0359.2014 \mathrm{v} 35 \mathrm{n} 2 \mathrm{p} 883$

Silva, M. E., Araujo, J. V., Silva, J. A., Carvalho, L. M., Chagas, E., \& Ribeiro, R. R. (2017). Anthelmintic efficacy of Cratylia argentea (Desv.) Kuntze against the gastrointestinal nematodes of sheep. Semina: Ciências Agrárias, 38 (5), 3105-3112. 10.5433/1679-0359.2017v38n5p3105

Silva, M. T. O., Maia, M. A. C., Silva, M. D. C., Torres, T. M., Pereira, J. C. S., Araujo, J. R. C., Silva, R. E., Souza, A. L. C., Barbosa, T. N., \&Bezerra, A. C. D. S. (2018). Anthelmintic effect of Cassia fistula and Combretum leprosum protein fractions against goat gastrointestinal nematodes. Brazilian Journal Veterinary Parasitology, 27, 237-241. 10.1590/S1984-296120180041

Silva, I. F., Guimarães, A. L., Amorim, V. S., T. M. G., Peixoto, R. M., Nunes, X. P., Silva, T. M. S., \& Costa, M. M. (2019). Antimicrobial Activity of ethanolic extracts from Commiphora leptophloeos (mart.) J.B. gillett against Staphylococcus spp. isolated from cases of mastitis in ruminants. Ciência Animal Brasileira, 20, 1-14. 10.1590/1089-6891v20e-57228

Silveira, R. X., Chagas, A. C. S., Botura, M. B., Batatinha, M. J. M., Katiti, L. M., Carvalho, C. O., Bevilaqua, C. M. L., Branco, A., Machado, E. A. A., Borges, S. L., \& Almeida, M. A. O. (2012). Action of sisal (Agave sisalana, Perrine) extract in the in vitro development of sheep and goat gastrointestinal nematodes. Experimental Parasitology, 131, 162-168. 10.1016/j.exppara.2012.03.018

Singh, R. (2015). Medicinal plants: A review. Journal of Plant Sciences, 3, 50-55. 10.11648/j.jps.s.2015030101.18

Sinott, M. C., Cunha, N. A. Fo., Castro, L. L. D, Lorenzon, L. B., Pinto, N. B., Capella, G. A., \&Leite, F. P. L. (2012). Bacillus spp. toxicity against Haemonchus contortus larva e in sheep fecal cultures. Experimental Parasitology,132, 103-108. 10.1016/j.exppara.2012.05.015. PMid:22728159

Soares, B. V., Moraes, S. M., Fontenelle, R. S. P., Brito, E. H. S., Queroz, V. A., Castro, C. M. S., Vila-Nova, N. S., Cavalcante, C. S. P., \& Rocha, M. F. G. (2015). Antifungal activity of plant extracts against Microsporum canis and Candida spp. Strains. Boletim, Latino americano y del Caribe de Plantas Medicinales y aromáticas, 14 (4), 263-272. https://pesquisa.bvsalud.org/portal/resource/pt/biblio-907489 
Research, Society and Development, v. 10, n. 8, e46710817223, 2021

(CC BY 4.0) | ISSN 2525-3409 | DOI: http://dx.doi.org/10.33448/rsd-v10i8.17223

Soares, B. V., Neves, L. R., Ferreira, D. O., Oliveira, M. S. B., Chaves, F. C. M., Chagas, E. C., Gonçalves, R. A.,\& Tavares-dias, M. (2016). Antiparasitic activity, histopathology and physiology of Colossoma macropomum (tambaqui) exposed to the essential oil of Lippia sidoides (Verbenaceae). Veterinary Parasitology, 234, 49-56. 10.1016/j.vetpar.2016.12.012

Souza, R. C., Costa, M. M., Baldisserotto, B., Heinzzmann, B. M., Schmit, D., Caron, B. O., \& Copatti, C. E. (2017). Antimicrobial and synergistic activity of essential oils of Aloysia triphylla and Lippia alba against Aeromonas spp. Microbial Pathogenesis, 113, 29-33. 10.1016/j.micpath.2017.10.013

Souza, E. M., Souza, R. C., Costa, M. M., Pinheiro, C. G., Heinzmann, B. E., \& Copatti, C. E. (2018). Chemical composition and evaluation of the antimicrobial activity of two essential oils. Boletim Instituto de Pesca, 44, 1-4. 10.20950/1678-2305.2018.321

Sperandio, J., Veleirinho, B., Honorato, L. A., Campestrini, L. H., \& Kuhnen, S. (2019). Atividade antimicrobiana e citotoxicidade in vitro do óleo essencial de Tagetes minuta L. visando à aplicação no controle da mastite bovina. Arquivo Brasileiro de Medicina Veterinária e Zootecnia, 71 (4), 1251-1259. 10.1590/1678$4162-10681$

Sprenger, L. K., Campestrini, L. H., Yamassaki, F. T., Bazatti, A., Maurer, J. B. B., Bagio, S. F. Z., Magalhães, P. M., \& Molento, M. B. (2015). Efeito anticoccidiano de extrato hidroalcoólico de Artemisia апnиа em camas de aves contaminadas com Eimeria sp. Pesquisa Veterinária Brasileira, 35, 649-65. $10.1590 / \mathrm{S} 0100-736$ X2015000700008

Tenório, R. F. L., Nascimento, M. S., Lima Filho, J. V. M., Maia, M. B. S., \& Coelho, M. C. O. C. (2016). Atividade Antibacteriana In Vitro do Extrato de Abarema cochliacarpos (Gomes) Barneby \& J.W. Grimes contra Bactérias Isoladas de Feridas Cutâneas de Cães. Ciência Animal Brasileira, 17 (2), $252-259$. $10.1590 / 1089-6891 v 17 \mathrm{i} 218391$

Varanda, E. A. (2006). Atividade mutagênica de plantas medicinais. Revista ciência Farmaceutica Básica Aplicada, 27 (1), 1-7. http://rcfba.fcfar.unesp.br/index.php/ojs/article/view/569

Verma, R. K. (2014). An ethnobotanical study of plants used for the treatment of livestock diseases in Tikamgarh District of Bundelkhand, Central India. Asian Pacific Journal of Tropical Biomedicine, 4 (1), S460-S467. 10.12980/APJTB.4.2014C1067

Vieira, P. B., Silva, N. L. F., Silva, D. B., Lopes, N. P., Silva, A. G., Silva, M. V., Batista, J., Macedo, A. J., \& Tasca, T. (2017). The Caatinga endemic Manilka rarufula possesses remarkable activity against Trichomonas vaginalis and Tritrichomonas foetus. Experimental Parasitology, 173, 18-28. 10.1016/j.exppara.2016.12.006

Vieira, D. S., Peixoto, R. M., Costa, M. M., Freire, D. P., Silva, T. M. G., \& Silva, T. M. (2018a). Atividade antimicrobiana in vitro do extrato etanólico bruto da folha da Hymenaea martiana Hayne frente às Staphylococcus spp. e avaliação de seu potencial como desinfetante em cabras. Pesquisa Veterinária Brasileira, 38 (3), 462-469. 10.1590/1678-5150-PVB-4547

Vieira, D. S., Moura, J. B., Silva, F. E. S., Taniwaki, F., \& Cardoso, T. C. 2018b. Atividade antitumoral da folha da Hymenaea martiana Hayne em células mamárias de cães. Pubvet, 12 (8), 1-6. 10.31533/pubvet.v12n8a149.1-6

Zaman, M. A., Iqbal, Z., Abbas, R. Z., Khan, M. N., Muhammad, G., Younus, M., \& Ahmed, S. (2012). In vitro and in vivo acaricidal activity of a herbal extract. Veterinary Parasitology, 186, 431-436. 10.1016/j.vetpar.2011.11.018

Ziech, R. E., Farias, L. D., Balzan, C., Ziech, M. F., Heinzmamm, B. M., Lameira, O. A., \& Vargas, A. C. (2013). Atividade antimicrobiana do oleorresina de copaíba (Copaifera reticulata) frente a Staphylococcus coagulase positiva isolados de casos de otite em cães. Pesquisa Veterinária Brasileira, 33 (7), $909-913$. 10.1590/S0100-736X2013000700011 